\title{
REVIEW
}

\section{Changing biological behaviour of NETs during the evolution of the disease: progress on progression}

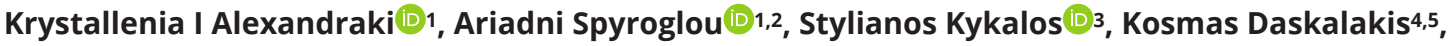 \\ Georgios Kyriakopoulos ${ }^{6}$, Georgios C Sotiropoulos², Gregory A Kaltsas ${ }^{5}$ and Ashley B Grossman ${ }^{7,8,9}$ \\ 1Second Department of Surgery, Aretaieion Hospital, National and Kapodistrian University of Athens, Athens, Greece \\ ${ }^{2}$ Clinic for Endocrinology, Diabetology and Clinical Nutrition, University Hospital Zurich, Zurich, Switzerland \\ 3Second Department of Propaedeutic Surgery, Laiko Hospital, National and Kapodistrian University of Athens, Medical School, Athens, Greece \\ ${ }^{4}$ Department of Surgery, Faculty of Medicine and Health, Örebro University, Örebro, Sweden \\ 5Endocrine Unit, First Department of Propaedeutic Medicine, Laiko University Hospital, Medical School, National and Kapodistrian University of Athens, \\ Athens, Greece \\ ${ }^{6}$ Department of Pathology, Evaggelismos Hospital, Athens, Greece \\ 7Oxford Centre for Diabetes, Endocrinology and Metabolism, Churchill Hospital, University of Oxford, Oxford, UK \\ 8NET Unit, Royal Free Hospital, London, UK \\ ${ }^{9}$ Barts and the London School of Medicine, London, UK
}

Correspondence should be addressed to K I Alexandraki: alexandrakik@gmail.com

\begin{abstract}
Following improvements in the management and outcome of neuroendocrine neoplasms (NENs) in recent years, we see a subset, particularly of pancreatic NENs, which become more aggressive during the course of the disease. This is reflected by an increase in the Ki-67 labelling index, as a marker of proliferation, which may lead to an occasion of increase in grading, but generally does not appear to be correlated with histologically confirmed dedifferentiation. A systematic review of the literature was performed in PubMed, Cochrane Library, and Embase until May 2020 to identify cases that have behaved in such a manner. We screened 244 articles: only seven studies included cases in their cohort, or in a subset of the cohort studied, with a proven increase in the Ki-67 during follow-up through additional biopsy. In addition to these studies, we have also tried to identify possible pathophysiological mechanisms implicated in advanced NENs, although currently no studies appear to have addressed the mechanisms implicated in the switch to a more aggressive biological phenotype over the course of the disease. Such progression of the disease course may demand a change in the management. Summarising the overall evidence, we suggest that future studies should concentrate on changes in the molecular pathways during disease progression with sequential biopsies in order to shed light on the mechanisms that render a neoplasm more aggressive than its initial phenotype or genotype.
\end{abstract}

\section{Key Words}

- neuroendocrine tumours

- molecular biology

- dedifferentiation

- Ki-67 index https://erc bioscientifica com https://doi.org/10.1530/ERC-20-0473
C 2021 Society for Endocrinology Published by Bioscientifica Ltd. Printed in Great Britain
Endocrine-Related Cancer (2021) 28, R121-R140 


\section{Introduction}

Neuroendocrine neoplasms (NENs) are tumours which are relatively rare but have shown an ongoing increase in their annual age-adjusted incidence, from 1.09/100,000 persons in 1973 to $6.98 / 100,000$ persons in 2012, according to the most recent database analyses from the National Cancer Institute's Surveillance, Epidemiology, and End Results (SEER) Program (Dasari et al. 2017).

Over the past few years, the terminology used to describe NENs has evolved in an attempt to reflect their biological behaviour, ranging from the welldifferentiated neuroendocrine tumours (NETs) to the poorly differentiated neuroendocrine carcinomas (NECs) (Nagtegaal et al. 2020). The Ki-67 protein is a cellular proliferation marker, useful for the determination of the growth capacity of an individual cell population. The grade in various tumour entities has been categorised based on their Ki-67 level of expression. Depending on their Ki-67 index, NENs are classified into well-differentiated NETs of grade G1, G2, or G3, or poorly differentiated G3 NECs (Nagtegaal et al. 2020), the boundaries of the grades depending on the specific tumour entity. Thus, both the degree of differentiation and the grade have been utilised as parameters to gauge the aggressiveness of NENs.

Heterogeneity of the neoplastic cellular population of NENs is a well-described histological characteristic of these neoplasms, with Ki-67 values varying both within the primary site and when compared to the synchronous metastatic foci (Miller et al. 2014, Singh et al. 2014, Richards-Taylor et al. 2017, Shi et al. 2018), or in relation to other pathological features, such as insulin-like growth factor IEc (IGF-IEc), chromogranin A (CgA) and synaptophysin expression (Alexandraki et al. 2017c). Such variation is also demonstrable in terms of the temporal course of the disease. It has been shown that, mainly in pancreatic NENs (pan-NENs), a change in their biological behaviour, as reflected by an increase in the Ki-67 proliferation index or even in their grade, may occur over time. This correlates with worse survival, particularly when occurring early (Hentic et al. 2017, Botling et al. 2020, Alexandraki et al. 2020). An additional example is the emergence of multiple or metachronous hormone secretion in functional NENs, this also correlating with worse survival (de Mestier et al. 2015, Crona et al. 2016, Zandee et al. 2017). Similarly, in some tumours a reduction in the expression of somatostatin receptors (SSTR) during sequential imaging with either 111Indium-pentetreotide or
${ }^{68}$ Gallium-1, 4, 7,10-tetraazacyclododecane-1,4, 7, 10tetraacetic acid - PET/CT ( ${ }^{68} \mathrm{Ga}$-DOTA-compounds PET/CT) - has been associated with an increase in tumoural uptake of ${ }^{18} \mathrm{~F}$-Fluorodeoxyglucose (FDG) PET/ $\mathrm{CT}$, implicating a change from a less to more aggressive behaviour (Paul et al. 2016, Chan et al. 2017, Carideo et al. 2019). One initial possible explanation was that NENs may dedifferentiate during the course of the disease in different areas within the tumour at varying times, and that this process might represent different tumoural sub-clones. However, it is difficult to identify such an accumulation of genetic alterations in NEN patients, although these are clearly present in other cancers (Fendrich et al. 2012, Cuny et al. 2018). Whether NETs and NECs represent two different forms of the same disease continuum, dependent on dedifferentiation, remains unclear; this is also due to the limitations in the number of tumours examined so far and their precise histopathology. Still, the recent WHO 2019 classification clearly separates NETs from NECs, suggesting that the latter may ab initio be quite distinct entities (WHO 2019). Accumulating evidence suggests that changes over time within a given NET do not lead to dedifferentiation per se but merely represent an increase in Ki-67 with the possible gain of some additional atypical features (i.e. necrosis or nuclear atypia) but with the maintenance of a well-differentiated morphology (Panzuto et al. 2017, Botling et al. 2020, Alexandraki et al. 2020). In most cases, such changes over time have been reported in pan-NENs (Panzuto et al. 2017, Botling et al. 2020, Alexandraki et al. 2020), with only few seen in those arising from the small bowel (SI), suggesting a dichotomy between pan-NENs' and SI-NENs' progression over time (Singh et al. 2014, Grillo et al. 2016, Panzuto et al. 2017, Shi et al. 2018). On the other hand, one hypothesis explaining the peculiar progressive biological behaviour of pan-NENs is that neoplasms can have different cellular origins with welldifferentiated G1 and G2, and also G3 NETs, originating from hormonally programmed neuroendocrine precursor cells, as opposed to poorly differentiated G3 NECs deriving from primitive neuroendocrine precursor cells (Kloppel 2017).

In this review, we will attempt to shed light on the phenomenon of the changes in tumour biology and behaviour over time, with particular reference to the questionable concept of 'dedifferentiation', by a critical appraisal of the current literature. The possible pathogenetic mechanisms involved in the process are explored and then linked to the diagnostic tools and therapeutic options available for patients with these neoplasms. 


\section{Materials and methods}

To identify studies and determine eligibility, we conducted a systematic review of the literature using the PubMed database. The search terms strategy included 'Cell Dedifferentiation/ etiology' (Mesh) OR 'Cell Dedifferentiation/genetics' (Mesh) OR 'Cell Dedifferentiation/immunolog' (Mesh) OR 'Cell Dedifferentiation/physiology' (Mesh) AND (Neuroendocrine Tumors/anatomy and histology' (Mesh) OR 'Neuroendocrine Tumors/epidemiology' (Mesh) OR 'Neuroendocrine Tumors/etiology' (Mesh) OR 'Neuroendocrine Tumors/genetics' (Mesh) OR 'Neuroendocrine Tumors/immunology' (Mesh) OR 'Neuroendocrine Tumors/pathology' (Mesh) OR 'Neuroendocrine Tumors/physiology' (Mesh) OR 'Neuroendocrine Tumors/physiopathology' (Mesh) OR 'Gastro-enteropancreatic neuroendocrine tumor' (Supplementary Concept). The databases were searched through until May 2020. We screened 244 articles: all articles were independently evaluated by four authors (K A, S K, A S, K D) for their relevance according to the research strategy. In addition, studies identified through reference lists were included. In spite of this extensive search, only seven studies included cases which described in their cohort - or in a subset of the cohort - an increase in the Ki-67 index during follow-up or between primary sites and metastases (Fig. 1).

\section{Results}

\section{Pathogenesis}

In order to investigate the molecular pathogenesis of NENs, especially pan-NENs, in the context of their evolution over time and alterations in biological behaviour during their natural history, three different hypotheses have been put forward: dedifferentiation of mature neuroendocrine cells, successive mutations within progenitors of neuroendocrine cells, and the loss of function of genes in non-neuroendocrine cells (Patel \& Galoian 2018), although these hypotheses are not mutually exclusive.

Dedifferentiation is a term used to describe the nuclear reprogramming of cancerous cells following a reverse developmental procedure from a well-differentiated to a less-differentiated status (Yu et al. 2014). This process has been well described in several cancers caused by oncogenic

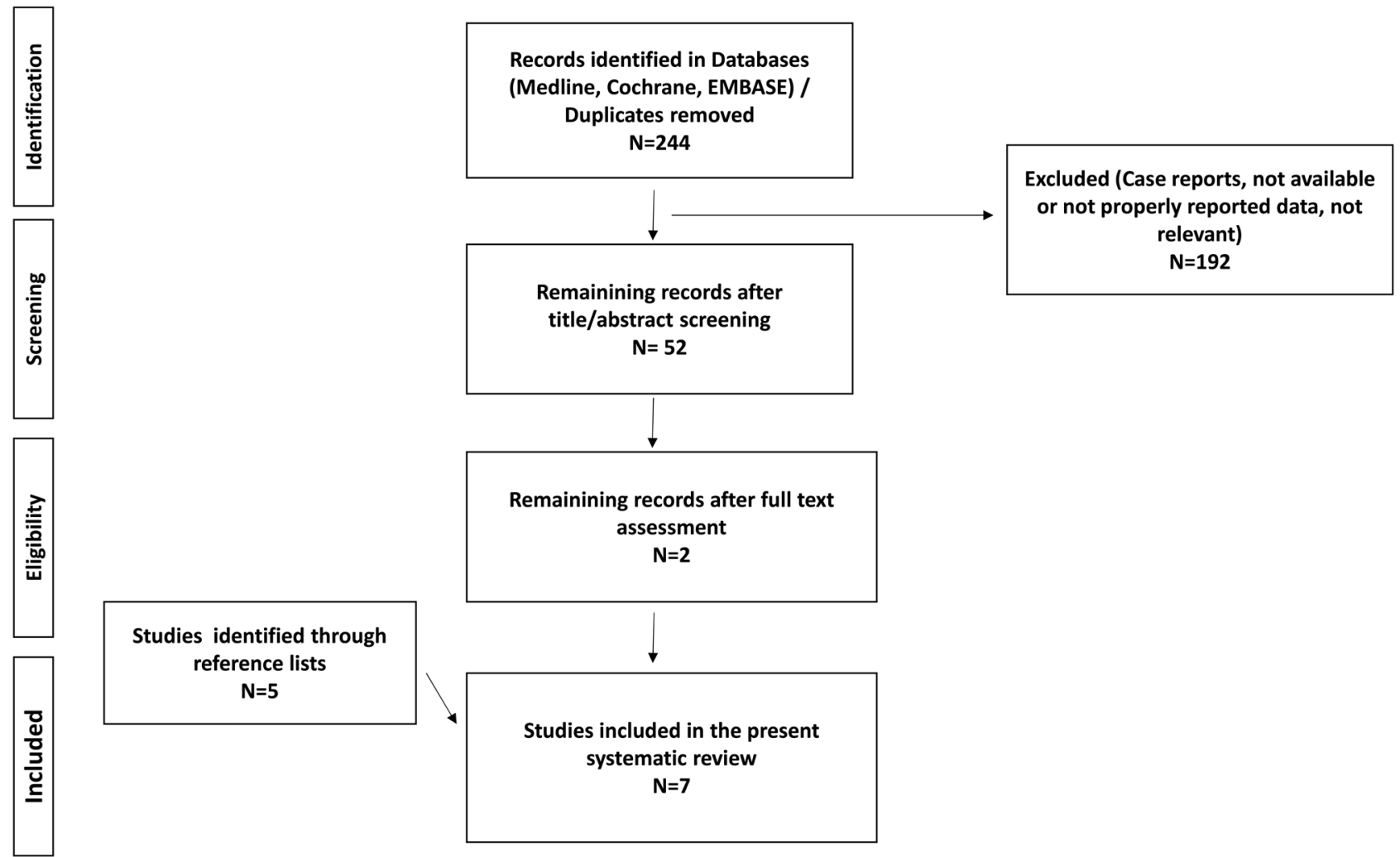

Figure 1

Flowchart for data collection. 
alterations in cancer cells but with increasing recognition of the significance of the tumour microenvironment (Friedmann-Morvinski \& Verma 2014). Thus, according to this view, the neuroendocrine tumour develops from mature neuroendocrine cells in a progressive ongoing process, with the accumulation of mutations (of oncogenes, tumour suppressor genes and others) that lead to a loss of various tissue-specific functions and hence, dedifferentiation to a less mature phenotype. In parallel, these accumulated mutations result in a more aggressive phenotype (Waldum et al. 2018). While the Ki-67 index provides information regarding cell proliferation, this is a separate and distinct phenomenon; it does seem to correlate well with the degree of differentiation of various tumours, so this cannot be considered synonymous with dedifferentiation.

\section{Molecular pathogenesis}

The molecular pathways leading to dedifferentiation may be responsible for the increase in clinical aggressiveness. During tumour progression, differentiation markers decrease, and stem/progenitor markers become more prominently expressed. Such dedifferentiation will require changes in the panoply of active transcription factors, for example, an increase in activity of the Wnt signalling pathway (Friedmann-Morvinski \& Verma 2014). Cadherins are a family of functionally related transmembrane glycoproteins responsible for the calcium-dependent, cell-cell adhesion mechanism of epithelial cells. A lack of E-cadherin (CDH1) expression is related to cellular dedifferentiation which also enhances the metastatic potential of tumours, also accounting for their poor prognosis (Li et al. 2002, Fougner et al. 2010). Down-regulation of E-cadherin expression is believed to be mostly induced by biochemical modification of the E-cadherin/catenin complex rather than by gene mutations, with the EGF receptor (EGFR) playing a central role. A proposed mechanism is activation of a cascade of tyrosine phosphorylation, caused by the interaction between transforming growth factor- $\alpha$ (TGFA) and EGFR, resulting in down-regulation of the E-cadherin/catenin complex and then nuclear $\beta$-catenin accumulation. These effects seem to play a direct role in tumour growth and progression in both well-differentiated NETs as well as poorly differentiated NECs. However, other mechanisms may also trigger dedifferentiation (Barth et al. 1997, Semba et al. 2000, Clavel et al. 2001, Li et al. 2002). Decreased or aberrant membranous and nuclear expression of E-cadherin, $\alpha$-catenin (CTNNA1), and $\beta$-catenin (CTNNB1) has been described in NENs of the gastrointestinal tract (for example, in liver metastases), in this case correlating with the process of dedifferentiation (Rosenau et al. 2002). While the presence of E-cadherin characterises most welldifferentiated NENs, Yonemori et al. have shown that the loss of E-cadherin promotes epithelial-mesenchymal transition (EMT) and correlates with a higher risk for vascular and lymphatic invasion, lymph node and liver metastasis (Yonemori et al. 2017). Similarly, loss of the E-cadherin/ $\beta$-catenin complex integrity and the increased expression of transcription repressors such as Snail-1 (SNAI1) correlate with the higher malignancy seen in both pulmonary NENs as well as pan-NENs (Fendrich et al. 2012, Galvan et al. 2013, 2014). In addition, overactivation of the Wnt/ $\beta$-catenin signalling pathway represents another mechanism leading to further progression of NETs (Wong et al. 2018); such overactivation may relate to mutations or epigenetic silencing of Wnt antagonists (Wnt inhibitors like Axin 2 (AXIN2) and secreted Frizzled-related proteins (SFRPs), Wnt inhibitory factor 1 (WIF 1) and DICKKOPFs (DKKs)) (Kim et al. 2013). While $\beta$-catenin shows membranous expression in pan-NENs unrelated to the histological grade of the tumour, some cases of advanced stage disease also showed nuclear $\beta$-catenin expression (Weiss et al. 2016). Loss of E-cadherin may cause such changes in the localisation of $\beta$-catenin, as it normally acts to sequester $\beta$-catenin in the membrane and, thus, to inhibit the proliferative action of the WNT pathway.

As noted previously for the EGFR, cell stimulation by various growth factors (GFs) and their concomitant signalling pathways contribute to EMT and facilitate invasion and dissemination. This may also relate to the tumour microenvironment, which can positively feedback onto the tumour cells, so enhancing their invasive and metastatic potential. In a further study, no clear correlation between loss of E-cadherin or Snail and Twist expression (as markers of EMT) could be shown with the occurrence of metastases in pan-NETs (Fendrich et al. 2012). While research in pancreatic and pulmonary cancers shows that even though EMT might not be essential for metastasis, it does seem to contribute to chemoresistance. The plasticity of the cancer cell can facilitate the development of therapy resistance and can also be the target of agents which reverse the process and inhibit metastasis (Pastushenko et al. 2018).

In gastroenteropancreatic NENs, various changes (genetic and epigenetic) affecting MEN1 and other complexes (e.g. SWI/SNF and the histone methylase complex) negatively influence chromatin remodelling. Specifically, alternative lengthening of telomeres (ALT) is not only associated with inactivation of the MEN1 gene
(C) 2021 Society for Endocrinology Published by Bioscientifica Ltd. Printed in Great Britain 
but also with functional loss of death domain-associated protein $(D A X X) / \alpha$-thalassemia/mental retardation X-linked (ATRX). ALT positivity, detected with large ultrabright nuclear telomere FISH signals, indicative of telomere length heterogeneity, correlates well with mutations of $D A X X / A T R X$ or loss of nuclear expression of either DAXX or ATRX (Heaphy et al. 2011). Tumours with functional loss of DAXX/ATRX are more aggressive, metastasise more frequently, and have a worse clinical outcome (Marinoni et al. 2014, Park et al. 2017, Singhi et al. 2017, Kyriakopoulos et al. 2018). However, in contrast, Jiao and colleagues observed prolonged survival in patients with the presence of DAXX/ATRX mutations (Jiao et al. 2011). This contradictory observation was further analysed in more detail: it seems that the impact of these two mutations on survival depends on the stage of the disease, with such mutations associated with worse prognosis in early-stage patients but longer survival when seen in metastatic cases (Boons et al. 2019). ALT positivity also demonstrates an association with an increased risk of metastasis in small pan-NENs (Pea et al. 2020). Furthermore, DAXX/ATRX has a feedback interaction with phosphatase and tensin homolog (PTEN), while its inactivation directly influences the PI3K/mTOR pathway (Yao et al. 2008). The PTEN gene negatively regulates the PI3K-AKT-mTOR pathway, inhibiting neoplastic cell survival and proliferation. It has been shown that the loss of PTEN increases pAKT expression which is associated with more aggressive behaviour in low-grade NETs and a shorter disease-free and overall survival of the patient (Missiaglia et al. 2010, Scarpa et al. 2017, Jayakumar et al. 2018, Uemura et al. 2019). The landscape of PI3K/mTOR pathway alterations has recently been enriched with new potential players, including DEPDC5 and EWSR1 fusions, and correlated with both the presence of DAXX/ATRX mutations and poor prognosis (Mafficini \& Scarpa 2018).

Mutations to DNA repair mechanisms appear to be involved not only in carcinogenesis but also in tumour aggressiveness as well. Thus, the mutY DNA glycosylase gene $(M U T Y H)$ plays a key role in the base excision repair mechanisms by protecting DNA exposed to oxidative stress, and it has been suggested that it is responsible for driving tumorigenesis of both familial and sporadic small intestinal as well as pan-NETs (Dumanski et al. 2017, Scarpa et al. 2017). Such a mutation would in turn increase the frequency of further disease-enhancing mutations.

In summary, down-regulation of E-cadherin expression, aberrant nuclear E-cadherin and $\alpha$ - and $\beta$-catenin expression, increased expression of transcription repressors such as Snail-1, mutations or epigenetic silencing of Wnt antagonists, functional loss of DAXX/ATRX, PTEN inactivation and increased pAKT expression can all lead to increased aggressiveness of NENs.

In pan-NETs, there is a well-described combination of pathways with DAXX/ATRX and MEN1 gene mutations predominantly present in well-differentiated NETs, while pan-NECs more frequently demonstrate mutations in tumour protein 53 (TP53), retinoblastoma (RB)1, cyclin-dependent kinase inhibitor 2A (CDKN2A), PTEN, phosphatidylinositol-4,5-bisphosphate 3-kinase (PI3K) catalytic subunit alpha (PI3KCA), KRAS, and SMAD4 (Hu et al. 2010, Oberg 2013, Singhi \& Klimstra 2018, Fang \& Shi 2019, Clift et al. 2020). Taken together, these pathways involve DNA damage repair, chromatin remodelling, ALT and PI3K/mTOR signalling (International Cancer Genome et al. 2010, Di Domenico et al. 2017, Scarpa et al. 2017). However, to date these two patterns of mutations appear quite distinct, and there is a lack of evidence that tumour progression in pan-NETs involves a shift from one pattern of mutations to another.

The pathological and molecular features that differentiate NETs and NECs, particularly in pancreatic neoplasms, have already been summarised (Singhi \& Klimstra 2018, Fang \& Shi 2019, Mafficini \& Scarpa 2019, Scarpa 2019). The prevalence of alterations in p53 is significantly higher in hepatic metastases than in primary pan-NENs (Gleeson et al. 2017). Additionally, several studies have shown that the oncoprotein p53 is almost always normally expressed in well-differentiated NETs but exhibits an abnormal pattern of either overexpression or a complete loss of expression in poorly differentiated NECs (Konukiewitz et al. 2017). Physiologically, p53 plays a crucial role in inducing differentiation and preventing dedifferentiation during tumorigenesis. Furthermore, it helps maintain the genomic stability of cells during the generation of induced-pluripotent stem (iPS) cells. Reprogramming factors such as MYC ProtoOncogene, BHLH Transcription Factor (c-Myc), Kruppel-like factor 4 (Klf4), POU class 5 Homeobox 1 (Oct4) and SRYbox transcription factor 2 (Sox2) may cause DNA damage, and thus, suppression of p53 favours the generation of iPS cells with persistent DNA damage and chromosomal aberrations. Inactivation of the p53 interaction factor CDKN2A accelerates the whole process (Yu et al. 2014) (Table 1). Thus, while one can pragmatically separate out the various pathways which are altered in pan-NENs, in practice they interweave and cross-regulate such that there is a complex interplay of factors, any one of which may contribute to tumorigenesis alone or in combination. What does appear to be reasonably clear is that, for the 
Table 1 Main genetic alterations in pancreatic, small intestine and lung NETs and NECs.

\begin{tabular}{|c|c|c|c|c|c|c|}
\hline Pathway & Pan-NETs & Pan-NECs & SI-NETS & SI-NECS & Lung-NETs & Lung-NECs \\
\hline Wnt/ $\beta$-catenin & RASSF1A & $\begin{array}{l}\text { APC } \\
\text { SMAD4 }\end{array}$ & $\begin{array}{l}\text { APC } \\
\text { EGFR } \\
\text { PDGFR } \\
\text { RASSF1A }\end{array}$ & $\begin{array}{l}\text { APC } \\
\text { CTNNB1 } \\
\text { RASSF1A } \\
\text { SMAD4 }\end{array}$ & & $\begin{array}{l}\text { CTNNB1 } \\
\text { SMAD4 }\end{array}$ \\
\hline $\mathrm{PI3K} / \mathrm{mTOR}$ & $\begin{array}{l}\text { PTEN } \\
\text { TSC2 } \\
\text { VHL }\end{array}$ & $\begin{array}{l}\text { BRAF } \\
\text { KRAS } \\
\text { PI3KCA }\end{array}$ & & $\begin{array}{l}\text { CXCL14 } \\
\text { BRAF } \\
\text { KRAS } \\
\text { SRC }\end{array}$ & PIK3CA & $\begin{array}{l}\text { KRAS } \\
\text { PTEN }\end{array}$ \\
\hline Chromatin remodelling & $\begin{array}{l}\text { ATM } \\
\text { MEN1 }\end{array}$ & & LOH18 & CNV 17q & $\begin{array}{l}\text { ARID1A } \\
\text { MEN1 } \\
\text { SMARCA2 } \\
\text { SMARCA4 }\end{array}$ & $\begin{array}{l}\text { ATM } \\
\text { CREBBP } \\
\text { KMT2D } \\
\text { SMARCA2 } \\
\text { SMARCA4 }\end{array}$ \\
\hline NOTCH signaling & & $\begin{array}{l}\text { HES1 } \\
\text { NOTCH1 }\end{array}$ & NOTCH1 & & & $\begin{array}{l}\text { ASCL1 } \\
\text { DLL3 } \\
\text { NOTCH1 }\end{array}$ \\
\hline DNA repair & MUTYH & TP53 & MUTYH & TP53 & & TP53 \\
\hline Cell cycle regulation & CDKN2A & RB1 & CDKN1B & RB1 & & $\begin{array}{l}\text { CDKN2A } \\
\text { RB1 }\end{array}$ \\
\hline Altered telomeres & $\begin{array}{l}\text { ATRX } \\
\text { DAXX }\end{array}$ & & & & & \\
\hline Miscellaneous & & & & $\begin{array}{l}\text { APLP1 } \\
\text { RUNX1 }\end{array}$ & EIF1AX & \\
\hline
\end{tabular}

Pan- and SI-NETs include well-differentiated G1 and G2 tumours and pan- and SI-NECs include poorly differentiated G3 tumours. Lung NETs include typical and atypical carcinoids whereas Lung-NECs include large and small cell neuroendocrine carcinomas.

Information retrieved from: Fernandez-Cuesta et al. (2014), Stalberg et al. (2016), Di Domenico et al. (2017), Pelosi et al. (2017), Scarpa et al. (2017), Simbolo et al. (2017, 2018, 2019), Derks et al. (2018), Fang \& Shi (2019), Mafficini \& Scarpa (2019), Samsom et al. (2019), Scarpa (2019), von Arx et al. (2019), Clift et al. (2020), Cros et al. (2020), Starzynska et al. (2020).

APC, APC regulator of WNT-signalling pathway; APLP1, amyloid beta precursor-like protein 1; ARID1A, AT-rich interaction domain 1A; ASCL1, achaetescute family BHLH transcription factor 1; ATM, ataxia-telangiectasia mutated (ATM serine/threonine kinase); ATRX, ATRX chromatin remodeler; ATRX, ATRX chromatin remodeler; BRAF, B-Raf proto-oncogene, serine/threonine kinase; CDKN1B, cyclin-dependent kinase inhibitor 1B; CDKN2A, cyclindependent kinase inhibitor 2A; CNV 17q, copy number variation chromosome 17q; CREBBP, CREB binding protein; CTNNB1, catenin beta 1; CXCL14, C-X-C motif chemokine ligand 14; DAXX, death domain-associated protein; DLL3, delta-like canonical Notch ;igand 3; EGFR, epidermal growth factor receptor; EIF1AX, eukaryotic translation initiation factor 1A X-linked; HES1, Hes family BHLH transcription factor 1; KMT2D, lysine methyltransferase 2D; KRAS, KRAS proto-oncogene, GTPase; LOH18, loss of heterozygosity chromosome 18; MEN1, Menin 1; MUTYH, MutY DNA glycosylase; NEC, neuroendocrine carcinoma; NET, neuroendocrine tumour; NOTCH1, Notch receptor 1; PDGFR, platelet-derived growth factor receptor beta; PI3KCA, phosphatidylinositol4,5-bisphosphate 3-kinase catalytic subunit alpha; PTEN, phosphatase and tensin homologue; RASSF1A, Ras association domain family member 1; RB1, RB transcriptional corepressor 1; RUNX1, RUNX family transcription factor 1; SI, small intestine; SMAD4, SMAD family member 4; SMARCA2, SWI/ SNF-related, matrix-associated, actin-dependent regulator of chromatin, subfamily A, member 2; SMARCA4, SWI/SNF-related, matrix-associated, actin-dependent regulator of chromatin, subfamily A, member 4; SRC, SRC proto-oncogene, non-receptor tyrosine kinase; TP53, tumour protein P53; TSC2, TSC complex subunit 2; VHL, Von Hippel-Lindau tumour suppressor.

most part, there is an obvious separation of pan-NETs, even when progressive, from pan-NECs.

In small intestine NENs (SI-NENs), the mutational landscape remains unclear, with tumours which harbour a loss of heterozygosity at chromosome 18 (LOH18), and $C D K N 1 B$ and adenomatous polyposis coli protein (APC) mutations, correlating with a poor prognosis (Stalberg et al. 2016, Di Domenico et al. 2017, Simbolo et al. 2018, Mafficini \& Scarpa 2019, Samsom et al. 2019, Scarpa 2019, Starzynska et al. 2020). A role for TP53 in the prognosis of these patients has not been clearly demonstrated to date (Ali et al. 2017). Liver metastases of SI-NENs more frequently display copy number variations (CNVs) and amplification of chromosome 17q, harbouring the
Her2/neu gene, correlating with a more aggressive phenotype (Karpathakis et al. 2017) (Table 1).

On the other hand, well-differentiated lung-NENs, such as typical and atypical carcinoids, carry alterations in MEN1, ARID1A, SMARC1, SMARCA2, whereas large and small cell lung carcinomas (NECs) show changes in RB1, TP53, PTEN, CDKN2A and NOTCH1 (Fernandez-Cuesta et al. 2014, Di Domenico et al. 2017, Pelosi et al. 2017, Simbolo et al. 2017, 2019, Derks et al. 2018, von Arx et al. 2019). Interestingly, in high-grade lung NENs comparative spatial/temporal analyses have confirmed that these tumours emerge from less aggressive clones which, though genetically-heterogeneous, then accumulate 'neuroendocrine carcinoma-like' genetic alterations and 
progress along with changes in TP53 and RB1 (Cros et al. 2020). Whether well-differentiated lung NETs might progress to more aggressive neoplasms, representing a paradigm shift from accepted pathogenesis schemes, has to be clarified (Ie \& Boyd 2015, Rekhtman et al. 2016, Pelosi et al. 2017, Quinn et al. 2017). The main genetic alterations observed in pan-NETs compared to pan-NECs, small intestine NETs compared to NECs and lung NETs and NECs are shown in Table 1.

\section{Epigenetic alterations}

Epigenetic changes, including DNA methylation and histone modification, also play a crucial role in NET progression (Friedmann-Morvinski \& Verma 2014). Hypermethylation in the RASSF1A gene may be observed in well-differentiated pancreatic, pulmonary and gastrointestinal NETs but is more pronounced in metastatic tumours and clearly correlates with a worse prognosis (Rahman et al. 2010, How-Kit et al. 2015). Methylation of two or more tumour suppressor genes correlated with liver metastases in a cohort of pancreatic and small intestine NENs (Liu et al. 2005). Further sites of promoter hypermethylation in tumours with a poor prognosis are found in various genes including DAPK1, TIMP3, PAX5, HIC1 and CADM1 (Stefanoli et al. 2014). Nevertheless, whether these alterations appear only with progression so far remains unclear. All these markers of aggressive disease may be putative markers of a neuroendocrine shift during the evolution of the disease.

\section{MicroRNAs}

MicroRNAs (miRNAs) are small, non-coding RNAs that regulate gene expression. More specifically, they interfere with processes such as cell growth, apoptosis, differentiation, and tumour development. They also play a pivotal role in cell-cell communication in tumour biology. Some miRNAs (e.g. miRNA-21 and -155) have been shown to be up-regulated in high-grade tumours but not in lowgrade ones, while others can be detected in metastatic low-grade tumours but not in normal tissues (Roldo et al. 2006). For our review, most relevant is the demonstration of the differential gene expression of miRNAs during different stages of progression of NENs of intestinal origin (Li et al. 2013). Furthermore, some miRNAs (miR-96, -182, -183) have been reported as overexpressed, while others are down-regulated (miR-129-5p and miR-133a), in small bowel NEN metastases compared to their primary lesion. For example, miRNA-133a was found to be downregulated during progression from primary to metastatic small intestine tumour, suggesting its potentially important role in the development and progression of NENs (Li et al. 2013). Similarly, miR-21 expression, which represses PTEN, is reported to be associated with a high proliferation index in insulinomas and their hepatic metastases (Roldo et al. 2006). It is also of interest that the blood levels of some miRNAs may be altered by treatment with somatostatin analogues (SSA but whether this is a specific treatment effect remains unclear (Malczewska et al. 2018, 2019).

\section{Tumour microenvironment}

Interleukin-6 (IL-6) induces cell proliferation, downregulates the expression of neuron-specific enolase (NSE), and it may stimulate tyrosine kinase phosphorylation of STAT3 signalling in non-small cell lung carcinomas that exhibit neuroendocrine properties (Poiana et al. 2013). In gastrointestinal NETs, higher IL-6 expression has been associated with disease progression, suggesting a potential modulation of their behaviour under inflammatory conditions (local and systemic) (Pereira et al. 2019). Thus, as previously noted, the tumour microenvironment plays a crucial role in determining NET aggressiveness.

One further pathogenetic mechanism is that associated with tumour hypoxia. The role of hypoxia in the genesis of NETs is unclear, but there is limited evidence that it may activate a dedifferentiated phenotype in other malignancies, such as ductal breast carcinoma or neuroblastoma (Axelson et al. 2005). Hypoxia induces up-regulation of proangiogenic factors, including the accumulation of hypoxia-inducible factor- $1 \alpha$ (HIF-1 $\alpha$ ), leading to a hypoxia-stress expression programme that includes many additional proangiogenic factors (Carmeliet 2005). Of the genes directly regulated by HIF-1, c-Met is involved in the invasive and metastatic behaviour of tumour cells on exposure to hypoxia. Although mTOR down-regulation during hypoxia leads to an increase of proangiogenic HIF-1 levels, an anti-angiogenic effect is observed during malignant transformation using mTOR inhibitors (Hudson et al. 2002, Bernardi et al. 2006, Thomas et al. 2006).

\section{Intratumoral heterogeneity and cell clones}

There are various molecular pathways by which subclones, of a relatively quiescent NET, may acquire some of the changes noted above, and thus, gain an 'evolutionary advantage' and become the dominant cancer in a heterogeneous tumour. Such heterogeneity can be demonstrated in many NETs by the demonstration 
of non-homogeneous radionuclide tracer uptake

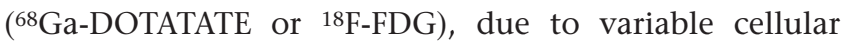
differentiation within the same tumour mass (Kayani et al. 2008). One example supporting this theory is given by pan-NET (insulinoma) cells lacking insulin-like growth factor II (IGF-II), which grow slowly in vitro but display a proliferation advantage in mixed cultures where they can access the IGF-II provided by other subclones, that is, IGF-II-producing cells (Archetti et al. 2015). Thus, intratumoural cell heterogeneity is advantageous to the tumour and such heterogeneity may persist. On the other hand, if a therapy targets a GF receptor, then subsequent loss of that GF may render the tumour refractory to further similar therapy (Archetti et al. 2015). Changes in the expression of IGF-I, IGF-II, IGF-IR, or their combinations, have been documented in various malignancies, and the role of the IGF system in metastasis, disease progression and poor prognosis has already been demonstrated in several human cancers (Samani et al. 2007). Accordingly, IGF-1Ec expression is increased in secondary compared to primary foci in NENs, predominantly in pan-NENs and small bowel NENs, when compared to less aggressive NENs originating from the appendix (Alexandraki et al. 2017c).

Circulating tumour cells (CTC) originate from a primary tumour and can become seeds for distant metastases. The expression of epithelial cell adhesion molecule (EpCAM) on their surface allows for their detection within the circulation. Strong homogeneous, membranous EpCAM expression was observed in ileal and pan-NETs, and CTC detection was associated with progressive NENs and could be used as prognostic marker. However, the differential expression of synaptophysin and CD-56 in CTCs from NENs suggest that CTCs are heterogeneous. This heterogeneity may have diagnostic implications as mutations may arise from the primary tumour per se or could occur de novo with the circulation, the latter possibly as an escape mechanism to a specific therapy (Khan et al. 2011). The CTC count does not correlate with either tumour Ki-67 or CgA expression, and thus, its role in NET progression remains unclear.

As an alternative to the gradual appearance of cancer cell clones with differing mutational profiles, with the less differentiated showing more aggressive characteristics and, hence, a selective advantage, the cancer stem cell (CSC) hypothesis has been proposed to explain tumour heterogeneity. It is noteworthy that mutations in the stem cells may generate the so-called CSCs which are pluripotent and able to self-renew. This subpopulation of stem-like cells plays a role in tumour growth, giving rise to highly heterogeneous tumour lesions (Visvader \& Lindeman 2008). Furthermore, the possibility of "'tumour cell plasticity"', where non-CSC can dedifferentiate and acquire CSC-like properties under certain conditions, has also been reported. Unfortunately, there are currently no data supporting this hypothesis with reference to NETs. It is unclear whether some CTCs are indeed CSCs. In animal models, 'aggressive' CTCs have been shown to colonise their tumour of origin with selfseeding. This may explain relationships between tumour size, vascularity, prognosis and local recurrence seeded by disseminated cells following complete excision (Kim et al. 2009). CSCs have also been identified in several NETs, including those arising in the pancreas, midgut, and bronchial NETs, the latter having the highest levels, and representing a potential therapeutic target for this entity (Gaur et al. 2011, Oberg et al. 2013).

\section{NET-specific therapeutic agents}

There is limited evidence that tumour progression may also be associated with NET-specific therapeutic agents. Although SSAs are associated with high symptomatic response rates in NETs, patients may develop resistance to treatment over time (De Martino et al. 2010). It is now suspected that truncated sst5 receptor variants with a distinct tissue distribution and cellular localisation display selective responses to somatostatin and its analogues (Duran-Prado et al. 2009). More specifically, two different sst5 receptor isoforms were recently identified, one with four (sstTMD4) and one with five transmembrane domains (sstTMD5). These isoforms are not expressed in the normal pituitary gland but are expressed in various other normal tissues and are also present in both functioning and non-functioning pituitary adenomas. They differentially respond to stimuli such as somatostatin and cortistatin, have distinct subcellular localisations, while the presence of the sst5TMD4 isoform correlates with increased aggressive features and a worse prognosis in somatotrophinomas. This provides a potentially useful tool to predict the outcome of clinical responses to SSAtherapy and the development of new therapeutic targets (Luque et al. 2015).

Similar considerations may apply to NENs. Basu et al. reported two cases of grade 2 NETs with a relatively high Ki-67 that showed a significant increase in SSTR expression following treatment with everolimus. The authors suggested that this agent might be associated with tumour redifferentiation (Basu \& Ostwal 2016). Furthermore, it may be noted that the improved progression-free survival (PFS) seen under combined long-acting octreotide and everolimus 
treatment of intermediate grade NETs may relate to a change in tumour genotype. However, the RADIANT trials showed that the combination of everolimus with octreotide LAR improved PFS but not overall survival in patients with advanced NENs, suggesting that redifferentiation as such effect may not actually occur (Pavel et al. 2011, 2017, Yao et al. 2011). Moreover, resistance to rapalogs/everolimus treatment has alternatively been attributed to various mechanisms such as PI3K/Akt/mTOR signalling mutations, activation of the PI3K/Akt/mTOR feedback loop, growth signalling mutations (FGFR4), activation of the Raf/MEK/ ERK pathway, dysregulation of the RB pathway, activation of PIM kinases, increased oxidative stress, stimulation of antiapoptotic signals and/or up-regulation of proangiogenic factors. On the other hand, sunitinib resistance seems to rely on alternative activation of proangiogenic signalling, with recruitment of bone-marrow-derived cells, an increase of pericyte coverage and lysosomal sequestration of the sunitinib (Beyens et al. 2019). Thus, such evidence implies that the development of tumour resistance to therapeutic agents may involve either a substitution of intracellular signalling pathways within a treated cell or the clonal escape of cells activating such alternative pathways rather than specific dedifferentiation. This can be shown to occur in the pan-NEN BON1 cell line in culture with everolimus (Aristizabal Prada et al. 2018).

In summary, there is strong evidence that the genetic interface of tumours is dynamic and may alter over time due to the accumulation of mutations (Burrell et al. 2013). This condition may lead to tumour heterogeneity due to the growth of several clonal patterns within the same tumour. Recently, Vandamme et al. reported on several genetic alterations being identifiable only within a small fraction of the respective tumour sample. The presence of such so-called 'low-abundance' mutations is in line with pan-NET heterogeneity and might explain tumour progression, and possibly dedifferentiation, during the course of the disease as these clones obtain a survival advantage (Vandamme et al. 2019). However, clear evidence for such dedifferentiation at a molecular or pathological level is lacking.

\section{Diagnostic tools for progression}

\section{Circulating markers}

NENs can secrete a wide range of amines and polypeptide hormones into the circulation. Classic biomarkers include CgA, NSE and pancreatic polypeptide as well as hormones that elicit clinical syndromes, such as serotonin, insulin, glucagon and gastrin. Given the complexity and heterogeneity of NENs as well as the interactions within the tumour microenvironment, no such biomarker has proven to be uniformly effective to estimate proliferation, metabolic activity or metastatic potential (Modlin et al. 2016). Of the common biomarkers investigated to date, CgA correlates better with the tumour burden and the biological activity of the NEN, especially in small bowel and pan-NENs, and can serve as an independent prognostic factor (Oberg 2011, Fuksiewicz et al. 2018). Nevertheless, there is no correlation between CgA levels and tumour mass in patients treated with SSAs, and CgA is not always sufficient for the detection of early recurrence with treatment (Oberg 2011). Although CgA does not have a very good sensitivity and specificity, it is more frequently elevated in G1 and G2 tumours compared to G3 NETs and can better predict prognosis in the subgroup of low-grade NETs (Modlin et al. 2010, Rossi et al. 2015). Patients with poorly differentiated NECs may present with neoplastic syndromes secondary to ectopic hormone production (e.g. ACTH) but rarely with the carcinoid syndrome or with functional hormone hypersecretion (Tang et al. 2016). Interestingly, as previously noted, the secondary appearance of hormonal secretion in an initially nonfunctional pan-NET (metachronous hormonal syndrome) correlates with the presence of metastases, radiological progression and worse survival, signs suggestive of tumour progression (de Mestier et al. 2015, Crona et al. 2016). Unlike pan-NETs, small bowel NETs are only rarely present with metachronous hormone secretion (Crona et al. 2016).

As previously described, methods for detecting circulating transcripts and tumour cells have been developed to improve diagnostic efficacy (Hofland et al. 2018). The detection of CTCs correlates to some degree with the tumour burden but only weakly or not at all with CgA or the tumour Ki-67 labelling index. The low number of NEN patients with detectable CTCs, together with the heterogeneity of these tumours, suggests that this biomarker currently requires further investigation. Specific miRNA overexpression or down-regulation has been reported with tumour progression in various NENs, as noted above, but a lack of standardisation of this method renders it unavailable for current clinical use. The presence of tumour-specific genetic alterations in cell-free (cf) DNA has recently been demonstrated in cases of metastatic pan-NETs, together with a clear correlation of the cf-DNA concentration with disease progression, suggestive of additional genetic alterations as drivers https://erc.bioscientifica.com

https://doi.org/10.1530/ERC-20-0473 (c) 2021 Society for Endocrinology Published by Bioscientifica Ltd. Printed in Great Britain 
for progressive disease (Boons et al. 2018). Ultrahighthroughput sequencing technology - whole-genome sequencing of germ-line DNA - might be used in the future to identify rare, highly penetrant, high-risk alleles that can be used to screen individuals at high risk. Evaluation of early- and late-stage samples could be used to identify biomarkers associated with progressive disease (Modlin et al. 2014). Furthermore, a NET liquid biopsy strategy with blood mRNA measurement (NETest) has been shown to have clinical utility in the accurate identification of NETs and their post-operative monitoring for the early identification of residual or metastatic disease (Malczewska et al. 2019, Laskaratos et al. 2020, Oberg et al. 2020). Thus, future and developing techniques will hopefully provide a more personalised molecular disease signature indicative of the disease status, progress and prognosis, and indicate appropriate tumour-based therapeutic options.

\section{Pathology}

According to the most recent 2019 WHO classification, the classification of a gastroenteropancreatic (GI)-NEN is based on both its differentiation and proliferative activity (Nagtegaal et al. 2020). Thus, well-differentiated G1 NETs present a mitotic count $<2 / 2 \mathrm{~mm}^{2}$ and/or a Ki-67 index $<3$ and G2 NETs have a mitotic count $2-20 / 2 \mathrm{~mm}^{2}$ and/or a Ki-67 index between 3-20\%. The latest group of NENs includes very heterogeneous neoplasms. Within the same histological grade, morphological features characterising these tumours are not uniform in all sites (Zatelli et al. 2018). Thus, the WHO classification of 2019 distinguishes between well-differentiated G3 NETs with a mitotic count $>20 / 2 \mathrm{~mm}^{2}$ and/or a Ki-67 >20\% and poorly differentiated NECs also with a mitotic count $>20 / 2 \mathrm{~mm}^{2}$ and/or a Ki-67 >20\% (Nagtegaal et al. 2020). On the other hand, the classification of lung NENs is based on mitoses and necrosis according to 2015 WHO classification. Typical carcinoid is defined by a mitotic count $<2$ mitoses $/ 2$ $\mathrm{mm}^{2}$ and lacking necrosis; atypical carcinoid is defined by a mitotic count $2-10$ mitoses $/ 2 \mathrm{~mm}^{2}$, and/or foci of necrosis. Large and small cell NECs are both characterised by extensive necrosis and a high mitotic count $(>10$ mitoses $/ 2 \mathrm{~mm}^{2}$ ) (Travis et al. 2015).

For GI-NENs, new 'sub-categories' suggested - but not yet adopted by the WHO - include: G3 NETs, with well-differentiated morphology and a Ki-67 of $21-55 \%$, G3 NECs with poorly differentiated morphology and a Ki-67 of 21-55\%, and finally NECs (tentatively referred to as G4) that are poorly differentiated and show a Ki-67 $>55 \%$ (Fazio \& Milione 2016, Pellat \& Coriat 2020).
However, even apparently well-differentiated NETs may include high-grade components in both primary and metastatic sites, occupying more than $20 \%$ of the tumour, with large heterogeneity in mitotic rate and Ki-67 index. While the presence of a high-grade component in well-differentiated pan-NETs was associated with an unfavourable clinical outcome, its prognosis is not as dismal as that of a truly poorly differentiated NEC (Tang et al. 2016). It is conceivable that NEN subclones of NETs might acquire further genetic changes and phenotypic features of NECs but overall retaining the characteristics of well-differentiated NENs. Even when the high-grade regions may resemble large-cell NECs, the association with a low-grade component may maintain these neoplasms in the well-differentiated NET group. Similarly, tumours at the site of metastasis have both the low/intermediate grade and the high-grade components. Morphological characteristics distinguishing G3 NETs from NECs are organoid growth pattern, capillary network in directcontact to tumour cells, and an absence of desmoplastic stroma; these characteristics also correlate with improved overall survival, suggestive of a less aggressive tumour behaviour (Elvebakken et al. 2020). Support for the dichotomy of the pan-NENs also comes from the observation that some G3 NENs with a Ki-67 index above 20\% show the typical DAXX/ATRX or MEN1 mutations but do not harbour TP53 or RB1 mutations and respond much better to therapies appropriate for well-differentiated NETs than to systemic platinum-based chemotherapy (Kloppel 2017). The large heterogeneity of pan-NENs can additionally be seen on investigation of the subcategories of small cell vs largecell G3 NECs, where one study demonstrated that small cell NECs display significantly lower SSTR-1 and SSTR-2A expression when compared to large-cell NECs (Mizutani et al. 2012). However, other studies could neither identify differential expression of immunohistochemical markers such as SSTR-2A, CgA and p53 nor differential genetic profiles between these two groups (Yachida et al. 2012, Nielsen et al. 2020). Histological examples of the large heterogeneity in these tumours can be found in Figs 2, 3 and 4 .

An increase in the Ki-67 index in metachronous metastases during the evolution of the disease has been assessed in terms of possible dedifferentiation. In several studies, particularly on pan-NETs, follow-up biopsy of the metastatic lesions along with clinical evidence of disease progression demonstrated an increase in the Ki-67 index, sometimes leading to progression to a highergrade NET (Singh et al. 2014, Grillo et al. 2016, Panzuto et al. 2017, Botling et al. 2020, Alexandraki et al. 2020). 


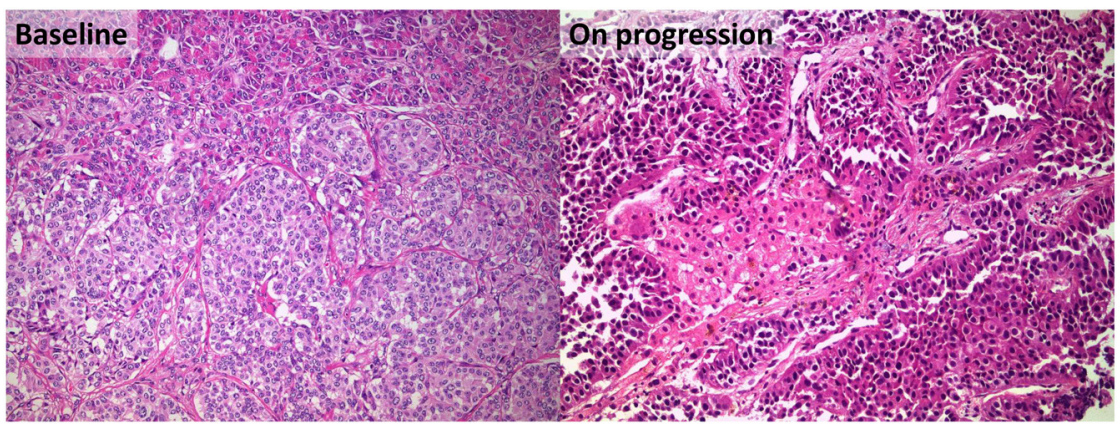

\section{Figure 2}

Haemotoxylin and Eosin staining of a pancreatic neuroendocrine neoplasm: before (left) and after (right) the increment in Ki-67 index.
More recently, morphological features usually associated with a NEC such as necrosis or nuclear atypia were observed during progression of a pan-NEN but lacking a clear dedifferentiated pattern (Botling et al. 2020) and displaying a change in tumour pathology over the progression of disease (Singh et al. 2014). PanNENs developed more aggressive growth characteristics compared to non-pan-NENs with not only an increase in Grade from G1 to G2 but also from G1 to G3 (Panzuto et al. 2017, Botling et al. 2020). High-grade progression with an increase in Ki-67 ranging from 17 to $55 \%$ has been reported. Similarly, we have recently presented a series of 15 patients with Pan-NENs with over-expression of p53 documented in three out of seven patients assessed but without clear evidence of histological dedifferentiation (Alexandraki et al. 2020). The main features of these seven studies are summarised in Table 2.

\section{Imaging}

Multiphasic contrast-enhanced abdominal and pelvic CT or MRI are the most common imaging modalities recommended for all patients with suspected NENs (Alexandraki et al. 2017b). For the evaluation of disease progression, multi-slice contrast-enhanced CT is the established technique for extra-hepatic lesions, while MRI is considered superior in the detection of hepatic lesions (Merino-Casabiel et al. 2018). Endoscopy and
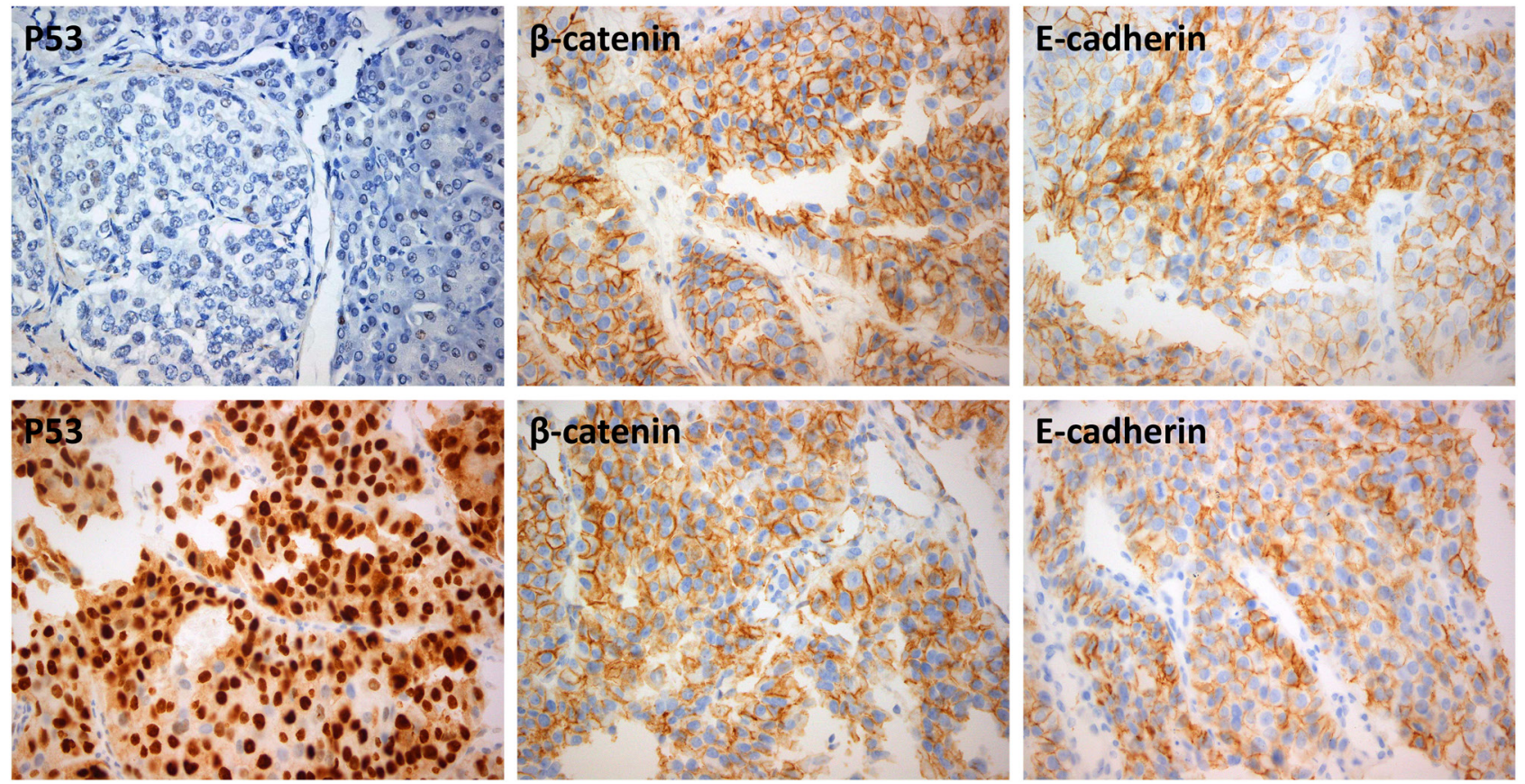

Figure 3

A pancreatic neuroendocrine neoplasm. Left panels: p53 immunohistochemical staining of the primary tumour (upper panel) and a metachronous liver metastasis (lower panel) with a markedly increased p53 expression in the metastasis in comparison to the initial pattern, with an increment in Ki-67 index from 5 to 70\%. Middle and right panels: the tumour (primary: upper panel - metastasis: lower panel) shows a retained pattern of membranous expression of $\beta$-catenin (middle) and E-cadherin (right).

https://erc.bioscientifica.com

https://doi.org/10.1530/ERC-20-0473 (c) 2021 Society for Endocrinology Published by Bioscientifica Ltd. Printed in Great Britain 

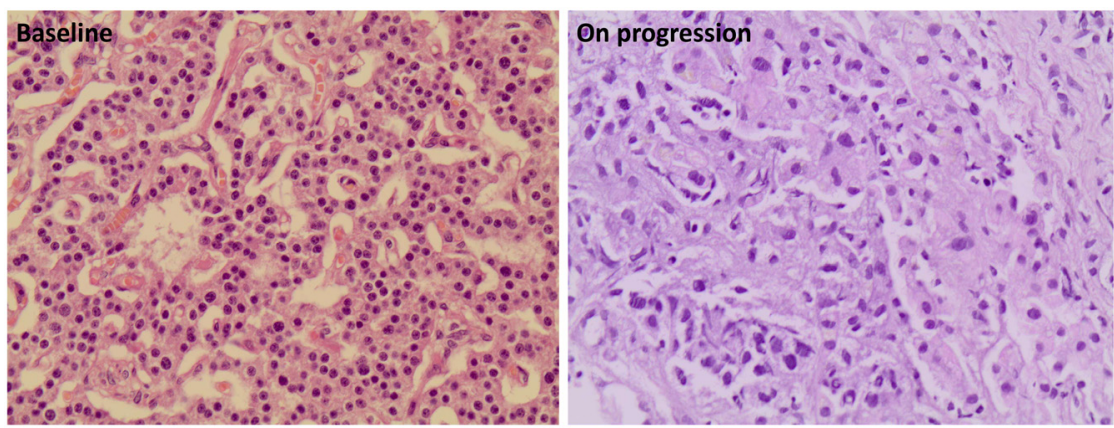

\section{Figure 4}

Left panel: A well-differentiated pancreatic neuroendocrine neoplasm with middle-sized uniform cells, round nuclei, salt-and-pepper chromatin, granulated cytoplasm, and a trabecular pattern, without crowding of the cells. Right panel: change to an atypical morphology, with nuclear polymorphism, with both round and spindle-shaped nuclei, dense chromatin and scant cytoplasm, with a solid growth pattern. endosonography combined with diagnostic biopsy can often be used for diagnosis (Alexandraki et al. 2017a, Daskalakis et al. 2019).

Until recently, the standard conventional modality for functional NET-imaging was SSTR imaging (SRI) scintigraphy with ${ }^{111}$ Indium-labelled pentetreotide (DTPA-octreotide, Octreoscan). ${ }^{18} \mathrm{~F}-$ fluorodihydroxyphenylalanine (18F-DOPA)-PET/CT or ${ }^{11} \mathrm{C}-5-$ hydroxytryptophan (5HTP)-PET/CT have also been used, especially if SRI is negative (Oberg 2012), whilst ${ }^{111}$ In-DOTA-exendin-4 (GLP-1R scintigraphy) is most helpful in cases with a high suspicion for the presence of an insulinoma (Antwi et al. 2019a), including patents with
MEN1 (Antwi et al. 2019b). However, ideally, SRI should nowadays be performed by PET (SRI-PET) when ${ }^{68}$ GalliumDOTA-TOC/-NOC/-TATE is available. SRI is indicated for the initial diagnosis of a small primary NET, for staging of the disease in a patient with a histologically proven NET, and pre-therapeutically in situations where peptide receptor radionuclide therapy (PRRT) is being considered. SRI-PET shows high sensitivity for most low-grade NETs but not in intermediate or high-grade pulmonary NETs (Tirosh \& Kebebew 2018). The usefulness of SRI for the follow-up of NET patients needs to be further validated (Antwi et al. 2019a). Interestingly, several studies have documented that a high SUVmax value correlates with

Table 2 Characteristics of studies investigating progression and de-differentiation in NENs.

\begin{tabular}{|c|c|c|c|c|c|}
\hline Study & $\begin{array}{l}\text { *No. of patients with } \\
\text { ki-67\% increase }\end{array}$ & Origin of NENs & $\begin{array}{l}\text { Ki-67\% at diagnosis } \\
\text { in the whole cohort }\end{array}$ & $\begin{array}{l}\text { Change in ki- } 67 \% \\
\text { in the whole } \\
\text { cohort }\end{array}$ & Grade upgrading \\
\hline $\begin{array}{l}\text { Alexandraki et al. } \\
2020\end{array}$ & $15 / 264$ & All pancreatic & 5\% (range: $1-25 \%$ ) & $\begin{array}{l}+45 \% \text { (range: }+6 \\
\text { to }+90 \%)\end{array}$ & $\begin{array}{l}2 \text { from G1 to G2; } \\
2 \text { from G1 to G3; } \\
1 \text { from low-to-high } \\
\text { G2; } \\
9 \text { from G2 to G3; } \\
1 \text { from low-to-high G3 }\end{array}$ \\
\hline Botling et al. 2020 & $34 / 46$ & All pancreatic & $\begin{array}{c}7 \% \text { (range } 1-38 \% \text { ), } \\
\text { G1 } n=8, \mathrm{G} 2 n= \\
36, \mathrm{G} 3 n=2\end{array}$ & $\begin{array}{l}+14 \% \text { (range }-11 \\
\text { to }+80 \%)\end{array}$ & $\begin{array}{l}7 \text { from } G 1 \text { to } G 2 ; \\
2 \text { from G1 to G3; } \\
25 \text { from } G 2 \text { to } G 3\end{array}$ \\
\hline Shi et al. 2018 & $12 / 30$ & GEP & $\mathrm{N} / \mathrm{A}$ & $\mathrm{N} / \mathrm{A}$ & $\begin{array}{l}\text { **4 from G1 to G2; } \\
1 \text { from G2 to G2; } \\
1 \text { from G2 to G3; } \\
6 \text { from G3 to G3 }\end{array}$ \\
\hline Panzuto et al. 2017 & $28 / 43$ & $\begin{array}{l}24 \text { pancreatic } \\
19 \text { small } \\
\text { intestine }\end{array}$ & $\begin{array}{l}3 \% \text { (range } 1-20 \% \text { in } \\
43 \text { ) }\end{array}$ & $\begin{array}{l}+5 \% \text { (range }+1 \text { to } \\
+70 \%) \text { in } 43\end{array}$ & $\begin{array}{l}8 \text { from G1 to G2 (6 } \\
\text { pan-NEN, } 2 \text { SI-NEN); } \\
4 \text { from G2 to G3 (all } \\
\text { pan-NEN) }\end{array}$ \\
\hline Grillo et al. 2016 & $\begin{array}{l}\text { 10/60 (metachronous } \\
\text { metastases) }\end{array}$ & GEP & N/A & N/A & $\begin{array}{l}9 \text { from } G 1 \text { to } G 2 ; \\
1 \text { from } G 2 \text { to } G 3\end{array}$ \\
\hline Shingh et al. 2014 & $12 / 43^{\dagger}$ & GEP, bronchial & $\mathrm{N} / \mathrm{A}$ & $\mathrm{N} / \mathrm{A}$ & $\begin{array}{l}5 \text { from } G 1 \text { to } G 2 ; \\
2 \text { from } G 2 \text { to } G 3 ; \\
5 \text { from } G 1 \text { to } G 3\end{array}$ \\
\hline Poiana et al. 2013 & 1 & Ovarian & $25-30 \%$ & $+40 \%$ & $\mathrm{~N} / \mathrm{A}$ \\
\hline
\end{tabular}

** Sixteen cases had change, (12 up-regulation, 4 down-regulation) but without distinction between the 10 cases with simultaneous detection and the 6 cases with the change during the course of the disease change in Ki-67; *patients with an increase in Ki-67/entire cohort; ${ }^{\dagger}$ patients with an increase in ki-67 leading to a change in grade.

G, grade; GEP, gastroenteropancreatic; NEN, neuroendocrine neoplasms.

https://erc bioscientifica com https://doi.org/10.1530/ERC-20-0473 (c) 2021 Society for Endocrinology Published by Bioscientifica Ltd. Printed in Great Britain 
a better clinical outcome, independent of the primary tumour site, suggesting this parameter as a good prognostic factor (Carideo et al. 2019).

As most NETs are well-differentiated tumours, they generally do not have a high glucose turnover rate. Thus, the sensitivity of ${ }^{18}$ F-FDG PET/CT is low, in particular in well-differentiated NETs (G1 and G2). As such, 18F-FDGPET is not routinely used for diagnostic purposes. However, poorly differentiated NETs (G3) display high glucose metabolism, usually associated with a poor prognosis. Most well-differentiated NETs, given their low proliferative activity, are usually negative on ${ }^{18}$ F-FDG-PET scans (Merino-Casabiel et al. 2018). Thus, SRI-PET is useful for the evaluation or progression of metastases in G1 NET patients, whereas in G2 NETs both ${ }^{18 F-F D G ~ a n d ~ S R I-P E T ~ c a n ~ b e ~ u t i l i s e d . ~ A d d i t i o n a l l y, ~}$ a 'flip/flop' phenomenon with negative ${ }^{18} \mathrm{~F}-\mathrm{FDG}$ PET but positive ${ }^{68} \mathrm{Ga}$-DOTA-TOC PET in some lesions and positive ${ }^{18} \mathrm{~F}$-FDG-PET but negative ${ }^{68} \mathrm{Ga}$-DOTA-TOC PET in other lesions, implying a synchronous heterogeneity in tumour aggressiveness, has also been observed (Nilica et al. 2016). Additionally, it has been suggested that ${ }^{18 F-F D G ~ P E T ~ s h o u l d ~ b e ~ l i m i t e d ~ t o ~ S R I-n e g a t i v e ~ N E T ~}$ patients, although G1-2 patients may also initially have ${ }^{18}$ F-FDG-negative tumours and may develop ${ }^{18} \mathrm{~F}-\mathrm{FDG}-$ positive lesions during follow-up. This latter group of lesions may represent the ones previously considered as 'dedifferentiated' or at least switching to a higher-grade NET. Gradually, NETs may present progression with some elements of dedifferentiation, losing their ability to express SSTR and increasing their metabolism, such that a positive correlation between the Ki-67 labelling index and ${ }^{18} \mathrm{~F}-\mathrm{FDG}-\mathrm{SUV}_{\max }$ has been documented in many studies (Carideo et al. 2019). As hypoxic cancerassociated fibroblasts that promote tumour progression carry out anaerobic glycolysis, high fibroblast density increases ${ }^{18} \mathrm{~F}$-FDG SUVmax, leading to intratumoral heterogeneity on functional imaging (Peppicelli et al. 2020). Adopting a dual-tracer approach, assessing SSTR expression and glycolytic metabolism, may, thus, support more individualised therapy selection in NET patients. The combination of ${ }^{18} \mathrm{~F}-\mathrm{FDG}$ and SRI-PET only slightly improves the accuracy of detection in pan-NETs in comparison to SRI-PET alone but significantly assisted in the characterisation of pulmonary NETs (Kayani et al. 2009, Partelli et al. 2014, Lococo et al. 2015). The combination of both modalities has a significant impact on the individual therapeutic approach, in particular by identifying high-risk lesions, which can be selected for biopsy/re-biopsy to identify changes in tumour biology (Tirosh \& Kebebew 2018). The use of combined 18 F-FDG and SRI-PET may also reveal areas of different tumour grading within the same lesion. Thus, dual imaging may provide relevant information which cannot be assessed by a single biopsy of a given metastatic lesion, as these may show heterogeneous metabolic activity and SSTR expression (Carideo et al. 2019). Dual imaging should generally be considered in G2 NETs, when there is heterogeneous SSTR expression of different tumour lesions, in patients with disease progression after prolonged stable disease, and in cases of discrepancy between conventional imaging and biochemical assessment.

Metabolic grading according to SRI or ${ }^{18} \mathrm{~F}-\mathrm{FDG}$ PET of ambiguous lesions allows prognostic stratification in metastatic GI-NENs, and the newly introduced NETPET scoring system combining results of ${ }^{18} \mathrm{~F}-\mathrm{FDG}$ and SRIPET can accurately describe the patient's disease burden (Ezziddin et al. 2014, Haug et al. 2014, Chan et al. 2017). Metabolic changes typically precede anatomic changes, and combination of these functional modalities enables early detection of poorly differentiated sites to redirect appropriate management (Hofman \& Hicks 2012, Merola et al. 2017). Similarly, 18F-FDG PET plays an important role in the assessment of the post-treatment response by identifying a significant metabolic response even in the absence of a corresponding morphological imaging response (Calabro et al. 2020).

\section{Management}

In the era of personalised treatment, the appropriate management of each NET patient depends on the stage of the disease at diagnosis along with symptoms, the grade of the neoplasm, and other factors such as patient comorbidities. The development of classification systems along with advances in anatomical and functional imaging should define a better risk stratification for each individual patient. In patients with tumour recurrence or metastatic foci recurrence and/or a rapid or unexpected progression in morphological or functional imaging studies, the re-evaluation of Ki-67 can play a role in producing a more accurate stratification. Thus, repeated biopsy in the recurrent mass or in the foci with the more aggressive features, or in new or rapidly growing tumour foci, can in these cases be useful. While clear dedifferentiation from a well-differentiated to a poorly differentiated phenotype is very rarely identified, an increase in the previous value of Ki-67 may dictate a change in treatment strategy (Knigge et al. 2017). The development of a new stratification score 
such as the NETPET scoring scheme may simplify the indications for a follow-up biopsy (Chan et al. 2017).

Surgery remains the mainstay of treatment for cure, but the substantial evolution of medical therapies allowed prolonged survival in cases with locally advanced or metastatic disease not amenable to surgical resection. Long-acting SSAs are usually the first-line treatment for functional and well-differentiated low-grade NENs, resulting in symptomatic control and mainly stabilisation of tumour growth; slow progression may necessitate an increase in dose or frequency. On progression, interferon- $\alpha$, targeted-therapy, either molecular or radionuclide (PRRT), or chemotherapy may follow and in a higher-grade NEN, immunotherapy may be used depending on the progression of the disease, imaging or histological features. Therapeutic agents are used in sequential order or in combination depending on tumour origin and differentiation, disease burden, clinical symptoms, and the patient's performance status (Tsoli et al. 2020). As tumours move along a path of progression, the appropriate therapy may change, and it is, therefore, important that the varying biochemical, pathological, and imaging modalities are considered. We have recently published a case with pan-NEN which progressed from G2 to G3, by increasing Ki-67 from 18 to $60 \%$, and has responded to nivolumab, an anti-programmed cell death 1 agent for more than 34 months (Koumarianou et al. 2021). This case illustrates the clinical utility of being aware of the biological progression of the tumour in order to optimise appropriate treatment.

Nevertheless, over time, there may be a change in the Ki-67 index (mean time in one study, 123 months or median time in another more recent study 36.8 months) with concomitant rapid disease progression leading to an adverse outcome, independent of treatment, in parallel with the histological evidence of change in grade (Grillo et al. 2016, Alexandraki et al. 2020). In the largest published study with pan-NENs, a negative outcome in terms of overall survival was documented in patients showing progression, with $83 \%$ patients in a cohort of 46 patients rapidly dying from their disease (Botling et al. 2020). Patients with progression to a high-grade (grade 3) NET had a shorter overall survival (median 50.2 months) compared to those without progression (median 115.1 months), resulting in a hazard ratio (HR) of 3.89 (95\% CI 1.91-7.94, $P<0.001$ ) (Botling et al. 2020). Progression from a low-grade to a high-grade NET based on the increase in Ki-67 index was selected as a useful prognostic marker. In a multivariate analysis including age, high-grade progression and change of disease behaviour, all three parameters remained independently correlated with a poor prognosis; HR 3.78 (95\% CI 1.72-8.69) for high-grade progression, HR 2.47 (95\% CI 1.042-5.87) for change of disease behaviour, and HR 1.057 (95\% CI 1.015-1.1) for age (Botling et al. 2020). Patients with progression to a high-grade pan-NET had a median survival of 12.2 months, while those without high-grade progression had a median survival of 51.6 months (HR 4.34, 95\% CI 2.02-9.35, $P<0.001$ ). Survival was also different among patients with any grade increase compared to those without an increase in grade, with a HR 2.95 (95\% CI 1.37-6.34, $P=0.006)$. Suspicion of a change in disease behaviour defined by clinical, biochemical, and/or radiological criteria, as stated by the authors, was also associated with a negative prognosis, HR 4.17 (95\% CI 1.9-9.13, $P<0.001$ ). Moreover, in our recent study with a similar design, a shorter overall survival was seen in patients who had a change in Ki-67 labelling index within the first 36 months of diagnosis, compared to those who had a change of Ki-67 at a later time point (Alexandraki et al. 2020). Documentation of such progression provides a strong prognostic factor and plays an important role in determining further therapeutic management (Singh et al. 2014, Grillo et al. 2016, Panzuto et al. 2017, Botling et al. 2020, Alexandraki et al. 2020) (Table 2).

\section{Conclusions}

A number of pathogenetic mechanisms has been identified to be involved in both the genesis and the progression of NENs but prognostically it is difficult to predict such changes. Many NENs, especially pan-NENs, progress over time, probably due to an accumulation of additional mutations leading in selective advantage of specific clones in a heterogeneous tumour but without leading to a true dedifferentiation process. This may be identified by changes in pathological characteristics of the biopsy, by biochemical markers, or by a switch from SSTR radionuclide activity to ${ }^{18} \mathrm{~F}$-FDG PET positivity, an important trait; these alterations will determine a change in therapeutic options. Indeed, there is also evidence that molecular therapy may lead to the development of resistance by the adaptation of signalling pathways (Vandamme et al. 2016, Aristizabal Prada et al. 2018). However, this progression will rarely lead to a true NEC, whose molecular pathogenesis appears to be determined by quite different factors to classic NETs, at least for gastroenteropancreatic NETs. Nevertheless, awareness of the time-dependent progression and processes of 
dedifferentiation are vital in selecting the most appropriate therapy at any particular time.

\section{Declaration of interest}

The authors declare that there is no conflict of interest that could be perceived as prejudicing the impartiality of this review.

\section{Funding}

This work did not receive any specific grant from any funding agency in the public, commercial, or not-for-profit sector.

\section{Author contribution statement}

A Spyroglou and $S$ Kykalos to be considered as equally contributing authors. A B Grossman and G A Kaltsas to be considered as joint senior authors.

\section{Acknowledgement}

The authors would like to thank S Theocharis for the histological figures.

\section{References}

Alexandraki K, Angelousi A, Boutzios G, Kyriakopoulos G, Rontogianni D \& Kaltsas G 2017a Management of neuroendocrine tumors of unknown primary. Reviews in Endocrine and Metabolic Disorders 18 423-431. (https://doi.org/10.1007/s11154-017-9437-9)

Alexandraki KI, Karapanagioti A, Karoumpalis I, Boutzios G \& Kaltsas GA 2017b Advances and current concepts in the medical management of gastroenteropancreatic neuroendocrine neoplasms. BioMed Research International 2017 9856140. (https://doi. org/10.1155/2017/9856140)

Alexandraki KI, Philippou A, Boutzios G, Theohari I, Koutsilieris M, Delladetsima IK \& Kaltsas GA 2017c IGF-IEc expression is increased in secondary compared to primary foci in neuroendocrine neoplasms. Oncotarget 8 79003-79011. (https://doi.org/10.18632/ oncotarget.20743)

Alexandraki KI, Kaltsatou M, Kyriakopoulos G, Mavroeidi V, Kostopoulou A, Atlan K, Theocharis S, Rindi G, Grossman AB, Grozinsky-Glasberg S, et al. 2020 Distinctive features of pancreatic neuroendocrine neoplasms exhibiting an increment in proliferative activity during the course of the disease. Endocrine [epub]. (https:// doi.org/10.1007/s12020-020-02540-w)

Ali AS, Gronberg M, Federspiel B, Scoazec JY, Hjortland GO, Gronbaek H, Ladekarl M, Langer SW, Welin S, Vestermark LW, et al. 2017 Expression of p53 protein in high-grade gastroenteropancreatic neuroendocrine carcinoma. PLoS ONE 12 e0187667. (https://doi. org/10.1371/journal.pone.0187667)

Antwi K, Nicolas G, Wild D \& Christ E 2019a Molecular imaging for neuroendocrine tumours. Swiss Medical Weekly 149 w20017. (https:// doi.org/10.4414/smw.2019.20017)

Antwi K, Nicolas G, Fani M, Heye T, Pattou F, Grossman A, Chanson P, Reubi JC, Perren A, Gloor B, et al. 2019b 68Ga-exendin-4 PET/CT detects insulinomas in patients with endogenous hyperinsulinemic hypoglycemia in MEN-1. Journal of Clinical Endocrinology and Metabolism 104 5843-5852. (https://doi.org/10.1210/jc.2018-02754)
Archetti M, Ferraro DA \& Christofori G 2015 Heterogeneity for IGF-II production maintained by public goods dynamics in neuroendocrine pancreatic cancer. PNAS 112 1833-1838. (https://doi.org/10.1073/ pnas.1414653112)

Aristizabal Prada ET, Spottl G, Maurer J, Lauseker M, Koziolek EJ, Schrader J, Grossman A, Pacak K, Beuschlein F, Auernhammer CJ, et al. 2018 The role of GSK3 and its reversal with GSK3 antagonism in everolimus resistance. Endocrine-Related Cancer 25 893-908. (https://doi.org/10.1530/ERC-18-0159)

Axelson H, Fredlund E, Ovenberger M, Landberg G \& Pahlman S 2005 Hypoxia-induced dedifferentiation of tumor cells - a mechanism behind heterogeneity and aggressiveness of solid tumors. Seminars in Cell and Developmental Biology 16 554-563. (https://doi.org/10.1016/j. semcdb.2005.03.007)

Barth AI, Nathke IS \& Nelson WJ 1997 Cadherins, catenins and APC protein: interplay between cytoskeletal complexes and signaling pathways. Current Opinion in Cell Biology 9 683-690. (https://doi. org/10.1016/s0955-0674(97)80122-6)

Basu S \& Ostwal V 2016 Observation on enhanced avidity on somatostatin receptor targeted 68Ga-DOTATATE PET-CT following therapy with everolimus and capecitabine-temozolamide: is redifferentiation akin phenomenon a reality in neuroendocrine tumors? Nuclear Medicine Communications 37 669-671. (https://doi. org/10.1097/MNM.0000000000000507)

Bernardi R, Guernah I, Jin D, Grisendi S, Alimonti A, Teruya-Feldstein J, Cordon-Cardo C, Simon MC, Rafii S \& Pandolfi PP 2006 PML inhibits HIF-1alpha translation and neoangiogenesis through repression of mTOR. Nature 442 779-785. (https://doi.org/10.1038/ nature05029)

Beyens M, Vandamme T, Peeters M, Van Camp G \& Op de Beeck K 2019 Resistance to targeted treatment of gastroenteropancreatic neuroendocrine tumors. Endocrine-Related Cancer 26 R109-R130. (https://doi.org/10.1530/ERC-18-0420)

Boons G, Vandamme T, Peeters M, Beyens M, Driessen A, Janssens K, Zwaenepoel K, Roeyen G, Van Camp G \& Op de Beeck K 2018 Cellfree DNA from metastatic pancreatic neuroendocrine tumor patients contains tumor-specific mutations and copy number variations. Frontiers in Oncology 8 467. (https://doi.org/10.3389/fonc.2018.00467)

Boons G, Vandamme T, Peeters M, Van Camp G \& Op de Beeck K 2019 Clinical applications of (epi)genetics in gastroenteropancreatic neuroendocrine neoplasms: moving towards liquid biopsies. Reviews in Endocrine and Metabolic Disorders 20 333-351. (https://doi. org/10.1007/s11154-019-09508-w)

Botling J, Lamarca A, Bajic D, Norlen O, Lonngren V, Kjaer J, Eriksson B, Welin S, Hellman P, Rindi G, et al. 2020 High-grade progression confers poor survival in pancreatic neuroendocrine tumors. Neuroendocrinology 110 891-898. (https://doi.org/10.1159/000504392)

Burrell RA, McGranahan N, Bartek J \& Swanton C 2013 The causes and consequences of genetic heterogeneity in cancer evolution. Nature 501 338-345. (https://doi.org/10.1038/nature12625)

Calabro D, Argalia G \& Ambrosini V 2020 Role of PET/CT and therapy management of pancreatic neuroendocrine tumors. Diagnostics 10 1059. (https://doi.org/10.3390/diagnostics10121059)

Carideo L, Prosperi D, Panzuto F, Magi L, Pratesi MS, Rinzivillo M, Annibale B \& Signore A 2019 Role of combined [(68)Ga]Ga-DOTASST analogues and [(18)F]FDG PET/CT in the management of GEPNENs: a systematic review. Journal of Clinical Medicine $\mathbf{8} 1032$. (https://doi.org/10.3390/jcm8071032)

Carmeliet P 2005 Angiogenesis in life, disease and medicine. Nature 438 932-936. (https://doi.org/10.1038/nature04478)

Chan DL, Pavlakis N, Schembri GP, Bernard EJ, Hsiao E, Hayes A Barnes T, Diakos C, Khasraw M, Samra J, et al. 2017 Dual somatostatin receptor/FDG PET/CT imaging in metastatic neuroendocrine tumours: proposal for a novel grading scheme with prognostic significance. Theranostics 7 1149-1158. (https://doi. org/10.7150/thno.18068) (c) 2021 Society for Endocrinology Published by Bioscientifica Ltd. Printed in Great Britain 
Clavel CE, Nollet F, Berx G, Tejpar S, Nawrocki-Raby B, Kaplan HH, van Roy FM \& Birembaut PL 2001 Expression of the E-cadherin-catenin complex in lung neuroendocrine tumours. Journal of Pathology 194 20-26. (https://doi.org/10.1002/path.868)

Clift AK, Kidd M, Bodei L, Toumpanakis C, Baum RP, Oberg K, Modlin IM \& Frilling A 2020 Neuroendocrine neoplasms of the small bowel and pancreas. Neuroendocrinology 110 444-476. (https:// doi.org/10.1159/000503721)

Crona J, Norlen O, Antonodimitrakis P, Welin S, Stalberg P \& Eriksson B 2016 Multiple and secondary hormone secretion in patients with metastatic pancreatic neuroendocrine tumours. Journal of Clinical Endocrinology and Metabolism 101 445-452. (https://doi.org/10.1210/ jc.2015-2436)

Cros J, Theou-Anton N, Gounant V, Nicolle R, Reyes C, Humez S, Hescot S, Thomas de Montpreville V, Guyetant S, Scoazec JY, et al. 2020 Specific genomic alterations in high grade pulmonary neuroendocrine tumours with carcinoid morphology. Neuroendocrinology 111 158-169. (https://doi. org/10.1159/000506292)

Cuny T, de Herder W, Barlier A \& Hofland LJ 2018 Role of the tumor microenvironment in digestive neuroendocrine tumors. EndocrineRelated Cancer 25 R519-R544. (https://doi.org/10.1530/ERC-18-0025)

Dasari A, Shen C, Halperin D, Zhao B, Zhou S, Xu Y, Shih T \& Yao JC 2017 Trends in the incidence, prevalence, and survival outcomes in patients with neuroendocrine tumors in the United States. JAMA Oncology 3 1335-1342. (https://doi.org/10.1001/ jamaoncol.2017.0589)

Daskalakis K, Tsoli M, Srirajaskanthan R, Chatzellis E, Alexandraki K, Angelousi A, Pizanias M, Randeva H, Kaltsas G \& Weickert MO 2019 Lung metastases in patients with well-differentiated gastroenteropancreatic neuroendocrine neoplasms: an appraisal of the validity of thoracic imaging surveillance. Neuroendocrinology 108 308-316. (https://doi.org/10.1159/000497183)

De Martino MC, Hofland LJ \& Lamberts SW 2010 Somatostatin and somatostatin receptors: from basic concepts to clinical applications. Progress in Brain Research 182 255-280. (https://doi.org/10.1016/ S0079-6123(10)82011-4)

de Mestier L, Hentic O, Cros J, Walter T, Roquin G, Brixi H, LombardBohas C, Hammel P, Diebold MD, Couvelard A, et al. 2015 Metachronous hormonal syndromes in patients with pancreatic neuroendocrine tumors: a case-series study. Annals of Internal Medicine 162 682-689. (https://doi.org/10.7326/M14-2132)

Derks JL, Leblay N, Lantuejoul S, Dingemans AC, Speel EM \& FernandezCuesta L 2018 New insights into the molecular characteristics of pulmonary carcinoids and large cell neuroendocrine carcinomas, and the impact on their clinical management. Journal of Thoracic Oncology 13 752-766. (https://doi.org/10.1016/j.jtho.2018.02.002)

Di Domenico A, Wiedmer T, Marinoni I \& Perren A 2017 Genetic and epigenetic drivers of neuroendocrine tumours (NET). EndocrineRelated Cancer 24 R315-R334. (https://doi.org/10.1530/ERC-17-0012)

Dumanski JP, Rasi C, Bjorklund P, Davies H, Ali AS, Gronberg M, Welin S, Sorbye H, Gronbaek H, Cunningham JL, et al. 2017 A MUTYH germline mutation is associated with small intestinal neuroendocrine tumors. Endocrine-Related Cancer 24 427-443. (https://doi.org/10.1530/ERC-17-0196)

Duran-Prado M, Gahete MD, Martinez-Fuentes AJ, Luque RM, Quintero A, Webb SM, Benito-Lopez P, Leal A, Schulz S, GraciaNavarro F, et al. 2009 Identification and characterization of two novel truncated but functional isoforms of the somatostatin receptor subtype 5 differentially present in pituitary tumors. Journal of Clinical Endocrinology and Metabolism 94 2634-2643. (https://doi. org/10.1210/jc.2008-2564)

Elvebakken H, Perren A, Scoazec JY, Tang LH, Federspiel B, Klimstra DS, Vestermark LW, Ali AS, Zlobec I, Myklebust TÅ, et al. 2020 A consensus developed morphological re-evaluation of 196 high-grade gastroenteropancreatic neuroendocrine neoplasms and its clinical correlations. Neuroendocrinology [epub]. (https://doi. org/10.1159/000511905)

Ezziddin S, Adler L, Sabet A, Poppel TD, Grabellus F, Yuce A, Fischer HP, Simon B, Holler T, Biersack HJ, et al. 2014 Prognostic stratification of metastatic gastroenteropancreatic neuroendocrine neoplasms by $18 \mathrm{~F}$ FDG PET: feasibility of a metabolic grading system. Journal of Nuclear Medicine 55 1260-1266. (https://doi.org/10.2967/ jnumed.114.137166)

Fang JM \& Shi J 2019 A clinicopathologic and molecular update of pancreatic neuroendocrine neoplasms with a focus on the new World Health Organization classification. Archives of Pathology and Laboratory Medicine 143 1317-1326. (https://doi.org/10.5858/ arpa.2019-0338-RA)

Fazio N \& Milione M 2016 Heterogeneity of grade 3 gastroenteropancreatic neuroendocrine carcinomas: new insights and treatment implications. Cancer Treatment Reviews 50 61-67. (https:// doi.org/10.1016/j.ctrv.2016.08.006)

Fendrich V, Maschuw K, Waldmann J, Buchholz M, Rehm J, Gress TM, Bartsch DK \& Konig A 2012 Epithelial-mesenchymal transition is a critical step in tumorgenesis of pancreatic neuroendocrine tumors. Cancers 4 281-294. (https://doi.org/10.3390/cancers4010281)

Fernandez-Cuesta L, Peifer M, Lu X, Sun R, Ozretic L, Seidal D, Zander T, Leenders F, George J, Muller C, et al. 2014 Frequent mutations in chromatin-remodelling genes in pulmonary carcinoids. Nature Communications 5 3518. (https://doi.org/10.1038/ ncomms4518)

Fougner SL, Lekva T, Borota OC, Hald JK, Bollerslev J \& Berg JP 2010 The expression of E-cadherin in somatotroph pituitary adenomas is related to tumor size, invasiveness, and somatostatin analog response. Journal of Clinical Endocrinology and Metabolism 95 2334-2342. (https://doi.org/10.1210/jc.2009-2197)

Friedmann-Morvinski D \& Verma IM 2014 Dedifferentiation and reprogramming: origins of cancer stem cells. EMBO Reports $\mathbf{1 5}$ 244-253. (https://doi.org/10.1002/embr.201338254)

Fuksiewicz M, Kowalska M, Kolasinska-Cwikla A, Cwikla JB, Sawicki Ł, Roszkowska-Purska K, Drygiel J \& Kotowicz B 2018 Prognostic value of chromogranin A in patients with GET/NEN in the pancreas and the small intestine. Endocrine Connections 7 803-810. (https://doi. org/10.1530/EC-18-0059)

Galvan JA, Astudillo A, Vallina A, Fonseca PJ, Gomez-Izquierdo L, Garcia-Carbonero R \& Gonzalez MV 2013 Epithelial-mesenchymal transition markers in the differential diagnosis of gastroenteropancreatic neuroendocrine tumors. American Journal of Clinical Pathology 140 61-72. (https://doi.org/10.1309/ AJCPIV40ISTBXRAX)

Galvan JA, Astudillo A, Vallina A, Crespo G, Folgueras MV \& Gonzalez MV 2014 Prognostic and diagnostic value of epithelial to mesenchymal transition markers in pulmonary neuroendocrine tumors. BMC Cancer 14 855. (https://doi.org/10.1186/1471-2407-14 855)

Gaur P, Sceusi EL, Samuel S, Xia L, Fan F, Zhou Y, Lu J, Tozzi F, LopezBerestein G, Vivas-Mejia P, et al. 2011 Identification of cancer stem cells in human gastrointestinal carcinoid and neuroendocrine tumors. Gastroenterology 141 1728-1737. (https://doi.org/10.1053/j. gastro.2011.07.037)

Gleeson FC, Voss JS, Kipp BR, Kerr SE, Van Arnam JS, Mills JR, Marcou CA, Schneider AR, Tu ZJ, Henry MR, et al. 2017 Assessment of pancreatic neuroendocrine tumor cytologic genotype diversity to guide personalized medicine using a custom gastroenteropancreatic next-generation sequencing panel. Oncotarget 8 93464-93475. (https://doi.org/10.18632/oncotarget.18750)

Grillo F, Albertelli M, Brisigotti MP, Borra T, Boschetti M, Fiocca R, Ferone D \& Mastracci L 2016 Grade increases in gastroenteropancreatic neuroendocrine tumor metastases compared to the primary tumor. Neuroendocrinology 103 452-459. (https://doi. org/10.1159/000439434)
C) 2021 Society for Endocrinology Published by Bioscientifica Ltd. Printed in Great Britain 
Haug AR, Cindea-Drimus R, Auernhammer CJ, Reincke M, Beuschlein F, Wangler B, Uebleis C, Schmidt GP, Spitzweg C, Bartenstein P, et al. 2014 Neuroendocrine tumor recurrence: diagnosis with 68Ga-DOTATATE PET/CT. Radiology 270 517-525. (https://doi. org/10.1148/radiol.13122501)

Heaphy CM, de Wilde RF, Jiao Y, Klein AP, Edil BH, Shi C, Bettegowda C, Rodriguez FJ, Eberhart CG, Hebbar S, et al. 2011 Altered telomeres in tumors with ATRX and DAXX mutations. Science 333 425. (https:// doi.org/10.1126/science.1207313)

Hentic O, Cros J, Rebours V, Zappa M, Muller N, Maire F, Levy P, Hammel P, Couvelard A \& Levy P 2017 Well-differentiated G1/G2 pancreatic NETs can evolve towards G3 tumors. In 14th Annual ENETS Conference 2017, pp Neuroendocrinology 105(suppl 101), 2017, 2011-2338. Barcelona, Spain.

Hofland J, Zandee WT \& de Herder WW 2018 Role of biomarker tests for diagnosis of neuroendocrine tumours. Nature Reviews: Endocrinology 14 656-669. (https://doi.org/10.1038/s41574-0180082-5)

Hofman MS \& Hicks RJ 2012 Changing paradigms with molecular imaging of neuroendocrine tumors. Discovery Medicine 14 71-81.

How-Kit A, Dejeux E, Dousset B, Renault V, Baudry M, Terris B \& Tost J 2015 DNA methylation profiles distinguish different subtypes of gastroenteropancreatic neuroendocrine tumors. Epigenomics 7 1245-1258. (https://doi.org/10.2217/epi.15.85)

Hu W, Feng Z, Modica I, Klimstra DS, Song L, Allen PJ, Brennan MF, Levine AJ \& Tang LH 2010 Gene amplifications in well-differentiated pancreatic neuroendocrine tumors inactivate the p53 pathway. Genes and Cancer 1 360-368. (https://doi. org/10.1177/1947601910371979)

Hudson CC, Liu M, Chiang GG, Otterness DM, Loomis DC, Kaper F Giaccia AJ \& Abraham RT 2002 Regulation of hypoxia-inducible factor 1alpha expression and function by the mammalian target of rapamycin. Molecular and Cellular Biology 22 7004-7014. (https://doi. org/10.1128/mcb.22.20.7004-7014.2002)

Ie S \& Boyd M 2015 New cancer or carcinoid progression to small cell lung cancer? Journal of Bronchology and Interventional Pulmonology 22 186-188. (https://doi.org/10.1097/LBR.0000000000000147)

International Cancer Genome Consortium, Hudson TJ, Anderson W, Artez A, Barker AD, Bell C, Bernabe RR, Bhan MK, Calvo F, Eerola I, et al. 2010 International network of cancer genome projects. Nature 464 993-998. (https://doi.org/10.1038/nature08987)

Jayakumar R, Lanjewar S \& Axiotis CA 2018 Loss of PTEN and increased pAKT expression distinguishes aggressive low-grade neuroendocrine tumors. Annals of Clinical and Laboratory Science 48 565-572.

Jiao Y, Shi C, Edil BH, de Wilde RF, Klimstra DS, Maitra A, Schulick RD, Tang LH, Wolfgang CL, Choti MA, et al. 2011 DAXX/ATRX, MEN1, and mTOR pathway genes are frequently altered in pancreatic neuroendocrine tumors. Science 331 1199-1203. (https://doi. org/10.1126/science.1200609)

Karpathakis A, Dibra H, Pipinikas C, Feber A, Morris T, Francis J, Oukrif D, Mandair D, Pericleous M, Mohmaduvesh M, et al. 2017 Progressive epigenetic dysregulation in neuroendocrine tumour liver metastases. Endocrine-Related Cancer 24 L21-L25. (https://doi. org/10.1530/ERC-16-0419)

Kayani I, Bomanji JB, Groves A, Conway G, Gacinovic S, Win T, Dickson J, Caplin M \& Ell PJ 2008 Functional imaging of neuroendocrine tumors with combined PET/CT using 68Ga-DOTATATE (DOTA-DPhe1,Tyr3-octreotate) and 18F-FDG. Cancer 112 2447-2455. (https://doi.org/10.1002/cncr.23469)

Kayani I, Conry BG, Groves AM, Win T, Dickson J, Caplin M \& Bomanji JB 2009 A comparison of 68Ga-DOTATATE and 18F-FDG PET/CT in pulmonary neuroendocrine tumors. Journal of Nuclear Medicine 50 1927-1932. (https://doi.org/10.2967/ jnumed.109.066639)

Khan MS, Tsigani T, Rashid M, Rabouhans JS, Yu D, Luong TV, Caplin M \& Meyer T 2011 Circulating tumor cells and EpCAM expression in neuroendocrine tumors. Clinical Cancer Research 17 337-345. (https://doi.org/10.1158/1078-0432.CCR-10-1776)

Kim MY, Oskarsson T, Acharyya S, Nguyen DX, Zhang XH, Norton L \& Massague J 2009 Tumor self-seeding by circulating cancer cells. Cell 139 1315-1326. (https://doi.org/10.1016/j.cell.2009.11.025)

Kim JT, Li J, Jang ER, Gulhati P, Rychahou PG, Napier DL, Wang C, Weiss HL, Lee EY, Anthony L, et al. 2013 Deregulation of Wnt/betacatenin signaling through genetic or epigenetic alterations in human neuroendocrine tumors. Carcinogenesis 34 953-961. (https://doi. org/10.1093/carcin/bgt018)

Kloppel G 2017 Neuroendocrine neoplasms: dichotomy, origin and classifications. Visceral Medicine 33 324-330. (https://doi. org/10.1159/000481390)

Knigge U, Capdevila J, Bartsch DK, Baudin E, Falkerby J, Kianmanesh R, Kos-Kudla B, Niederle B, Nieveen van Dijkum E, O'Toole D, et al. 2017 Enets consensus recommendations for the standards of care in neuroendocrine neoplasms: follow-up and documentation. Neuroendocrinology 105 310-319. (https://doi. org/10.1159/000458155)

Konukiewitz B, Schlitter AM, Jesinghaus M, Pfister D, Steiger K, Segler A, Agaimy A, Sipos B, Zamboni G, Weichert W, et al. 2017 Somatostatin receptor expression related to TP53 and RB1 alterations in pancreatic and extrapancreatic neuroendocrine neoplasms with a Ki67-index above 20. Modern Pathology 30 587-598. (https://doi.org/10.1038/ modpathol.2016.217)

Koumarianou A, Kaltsas GA, Chatzellis E, Kyriakopoulos G, Kolomodi D \& Alexandraki KI 2021 Immunotherapeutics at the spearhead: current status in targeting neuroendocrine neoplasms. Endocrine. (https://doi.org/10.1007/s12020-021-02639-8)

Kyriakopoulos G, Mavroeidi V, Chatzellis E, Kaltsas GA \& Alexandraki KI 2018 Histopathological, immunohistochemical, genetic and molecular markers of neuroendocrine neoplasms. Annals of Translational Medicine 6 252. (https://doi.org/10.21037/ atm.2018.06.27)

Laskaratos FM, Liu M, Malczewska A, Ogunbiyi O, Watkins J, Luong TV, Mandair D, Caplin M \& Toumpanakis C 2020 Evaluation of circulating transcript analysis (NETest) in small intestinal neuroendocrine neoplasms after surgical resection. Endocrine 69 430-440. (https://doi.org/10.1007/s12020-020-02289-2)

Li CC, Xu B, Hirokawa M, Qian Z, Yoshimoto K, Horiguchi H, Tashiro T \& Sano T 2002 Alterations of E-cadherin, alpha-catenin and betacatenin expression in neuroendocrine tumors of the gastrointestinal tract. Virchows Archiv 440 145-154. (https://doi.org/10.1007/ s004280100529)

Li SC, Essaghir A, Martijn C, Lloyd RV, Demoulin JB, Oberg K \& Giandomenico V 2013 Global microRNA profiling of welldifferentiated small intestinal neuroendocrine tumors. Modern Pathology 26 685-696. (https://doi.org/10.1038/modpathol.2012.216)

Liu L, Broaddus RR, Yao JC, Xie S, White JA, Wu TT, Hamilton SR \& Rashid A 2005 Epigenetic alterations in neuroendocrine tumors: methylation of RAS-association domain family 1, isoform A and p16 genes are associated with metastasis. Modern Pathology 18 1632-1640. (https://doi.org/10.1038/modpathol.3800490)

Lococo F, Perotti G, Cardillo G, De Waure C, Filice A, Graziano P, Rossi G, Sgarbi G, Stefanelli A, Giordano A, et al. 2015 Multicenter comparison of 18F-FDG and 68Ga-DOTA-peptide PET/CT for pulmonary carcinoid. Clinical Nuclear Medicine 40 e183-e189. (https://doi.org/10.1097/RLU.0000000000000641)

Luque RM, Ibanez-Costa A, Neto LV, Taboada GF, Hormaechea-Agulla D, Kasuki L, Venegas-Moreno E, Moreno-Carazo A, Galvez MÁ, SotoMoreno A, et al. 2015 Truncated somatostatin receptor variant sst5TMD4 confers aggressive features (proliferation, invasion and reduced octreotide response) to somatotropinomas. Cancer Letters 359 299-306. (https://doi.org/10.1016/j.canlet.2015.01.037)

Mafficini A \& Scarpa A 2018 Genomic landscape of pancreatic neuroendocrine tumours: the International Cancer Genome (c) 2021 Society for Endocrinology Published by Bioscientifica Ltd. Printed in Great Britain 
Consortium. Journal of Endocrinology 236 R161-R167. (https://doi. org/10.1530/JOE-17-0560)

Mafficini A \& Scarpa A 2019 Genetics and epigenetics of gastroenteropancreatic neuroendocrine neoplasms. Endocrine Reviews 40 506-536. (https://doi.org/10.1210/er.2018-00160)

Malczewska A, Kidd M, Matar S, Kos-Kudla B \& Modlin IM 2018 A comprehensive assessment of the role of miRNAs as biomarkers in gastroenteropancreatic neuroendocrine tumors. Neuroendocrinology 107 73-90. (https://doi.org/10.1159/000487326)

Malczewska A, Bodei L, Kidd M \& Modlin IM 2019 Blood mRNA measurement (NETest) for neuroendocrine tumor diagnosis of imagenegative liver metastatic disease. Journal of Clinical Endocrinology and Metabolism 104 867-872. (https://doi.org/10.1210/jc.2018-01804)

Marinoni I, Kurrer AS, Vassella E, Dettmer M, Rudolph T, Banz V, Hunger F, Pasquinelli S, Speel EJ \& Perren A 2014 Loss of DAXX and ATRX are associated with chromosome instability and reduced survival of patients with pancreatic neuroendocrine tumors. Gastroenterology 146 453.e5-460.e5. (https://doi.org/10.1053/j. gastro.2013.10.020)

Merino-Casabiel X, Aller J, Arbizu J, Garcia-Figueiras R, Gonzalez C, Grande E, Jimenez-Fonseca P, Sevilla MI \& Capdevila J 2018 Consensus document on the progression and treatment response criteria in gastroenteropancreatic neuroendocrine tumors. Clinical and Translational Oncology 20 1522-1528. (https://doi.org/10.1007/ s12094-018-1881-9)

Merola E, Pavel ME, Panzuto F, Capurso G, Cicchese N, Rinke A, Gress TM, Iannicelli E, Prosperi D, Pizzichini P, et al. 2017 Functional imaging in the follow-up of enteropancreatic neuroendocrine tumors: clinical usefulness and indications. Journal of Clinical Endocrinology and Metabolism 102 1486-1494. (https://doi. org/10.1210/jc.2016-3732)

Miller HC, Drymousis P, Flora R, Goldin R, Spalding D \& Frilling A 2014 Role of Ki-67 proliferation index in the assessment of patients with neuroendocrine neoplasias regarding the stage of disease. World Journal of Surgery 38 1353-1361. (https://doi.org/10.1007/s00268014-2451-0)

Missiaglia E, Dalai I, Barbi S, Beghelli S, Falconi M, della Peruta M, Piemonti L, Capurso G, Di Florio A, delle Fave G, et al. 2010 Pancreatic endocrine tumors: expression profiling evidences a role for AKT-mTOR pathway. Journal of Clinical Oncology 28 245-255. (https://doi.org/10.1200/JCO.2008.21.5988)

Mizutani G, Nakanishi Y, Watanabe N, Honma T, Obana Y, Seki T, Ohni S \& Nemoto N 2012 Expression of somatostatin receptor (SSTR) subtypes (SSTR-1, 2A, 3, 4 and 5) in neuroendocrine tumors using real-time RT-PCR method and immunohistochemistry. Acta Histochemica et Cytochemica 45 167-176. (https://doi.org/10.1267/ ahc.12006)

Modlin IM, Gustafsson BI, Moss SF, Pavel M, Tsolakis AV \& Kidd M 2010 Chromogranin A - biological function and clinical utility in neuro endocrine tumor disease. Annals of Surgical Oncology 17 2427-2443. (https://doi.org/10.1245/s10434-010-1006-3)

Modlin IM, Oberg K, Taylor A, Drozdov I, Bodei L \& Kidd M 2014 Neuroendocrine tumor biomarkers: current status and perspectives. Neuroendocrinology 100 265-277. (https://doi.org/10.1159/000368363)

Modlin IM, Bodei L \& Kidd M 2016 Neuroendocrine tumor biomarkers: From monoanalytes to transcripts and algorithms. Best Practice and Research: Clinical Endocrinology and Metabolism 30 59-77. (https://doi. org/10.1016/j.beem.2016.01.002)

Nagtegaal ID, Odze RD, Klimstra D, Paradis V, Rugge M, Schirmacher P, Washington KM, Carneiro F, Cree IA \& WHO Classification of Tumours Editorial Board 2020 The 2019 WHO classification of tumours of the digestive system. Histopathology 76 182-188. (https:// doi.org/10.1111/his.13975)

Nielsen K, Binderup T, Langer SW, Kjaer A, Knigge P, Grondahl V, Melchior L, Federspiel B \& Knigge U 2020 P53, somatostatin receptor $2 \mathrm{a}$ and chromogranin A immunostaining as prognostic markers in high grade gastroenteropancreatic neuroendocrine neoplasms. BMC Cancer 20 27. (https://doi.org/10.1186/s12885-019-6498-z)

Nilica B, Waitz D, Stevanovic V, Uprimny C, Kendler D, Buxbaum S, Warwitz B, Gerardo L, Henninger B, Virgolini I, et al. 2016 Direct comparison of (68)Ga-DOTA-TOC and (18)F-FDG PET/CT in the follow-up of patients with neuroendocrine tumour treated with the first full peptide receptor radionuclide therapy cycle. European Journal of Nuclear Medicine and Molecular Imaging 43 1585-1592. (https://doi. org/10.1007/s00259-016-3328-2)

Oberg K 2011 Circulating biomarkers in gastroenteropancreatic neuroendocrine tumours. Endocrine-Related Cancer 18 (Supplement 1) S17-S25. (https://doi.org/10.1530/ERC-10-0280)

Oberg K 2012 Diagnostic work-up of gastroenteropancreatic neuroendocrine tumors. Clinics 67 (Supplement 1) 109-112. (https:// doi.org/10.6061/clinics/2012(sup01)18)

Oberg K 2013 The genetics of neuroendocrine tumors. Seminars in Oncology 40 37-44. (https://doi.org/10.1053/j. seminoncol.2012.11.005)

Oberg K, Casanovas O, Castano JP, Chung D, Delle Fave G, Denefle P, Harris P, Khan MS, Kulke MH, Scarpa A, et al. 2013 Molecular pathogenesis of neuroendocrine tumors: implications for current and future therapeutic approaches. Clinical Cancer Research 19 2842-2849. (https://doi.org/10.1158/1078-0432.CCR-12-3458)

Oberg K, Califano A, Strosberg JR, Ma S, Pape U, Bodei L, Kaltsas G, Toumpanakis C, Goldenring JR, Frilling A, et al. 2020 A metaanalysis of the accuracy of a neuroendocrine tumor mRNA genomic biomarker (NETest) in blood. Annals of Oncology 31 202-212. (https://doi.org/10.1016/j.annonc.2019.11.003)

Panzuto F, Cicchese N, Partelli S, Rinzivillo M, Capurso G, Merola E, Manzoni M, Pucci E, Iannicelli E, Pilozzi E, et al. 2017 Impact of Ki67 re-assessment at time of disease progression in patients with pancreatic neuroendocrine neoplasms. PLOS ONE 12 e0179445. (https://doi.org/10.1371/journal.pone.0179445)

Park JK, Paik WH, Lee K, Ryu JK, Lee SH \& Kim YT 2017 DAXX/ATRX and MEN1 genes are strong prognostic markers in pancreatic neuroendocrine tumors. Oncotarget 8 49796-49806. (https://doi. org/10.18632/oncotarget.17964)

Partelli S, Rinzivillo M, Maurizi A, Panzuto F, Salgarello M, Polenta V, Delle Fave G \& Falconi M 2014 The role of combined Ga-DOTANOC and (18)FDG PET/CT in the management of patients with pancreatic neuroendocrine tumors. Neuroendocrinology 100 293-299. (https:// doi.org/10.1159/000368609)

Pastushenko I, Brisebarre A, Sifrim A, Fioramonti M, Revenco T, Boumahdi S, Van Keymeulen A, Brown D, Moers V, Lemaire S, et al. 2018 Identification of the tumour transition states occurring during EMT. Nature 556 463-468. (https://doi.org/10.1038/s41586-0180040-3)

Patel P \& Galoian K 2018 Molecular challenges of neuroendocrine tumors. Oncology Letters 15 2715-2725. (https://doi.org/10.3892/ ol.2017.7680)

Paul D, Ostwal V, Bose S, Basu S \& Gupta S 2016 Personalized treatment approach to gastroenteropancreatic neuroendocrine tumors: a medical oncologist's perspective. European Journal of Gastroenterology and Hepatology 28 985-990. (https://doi.org/10.1097/ MEG.0000000000000674)

Pavel ME, Hainsworth JD, Baudin E, Peeters M, Horsch D, Winkler RE, Klimovsky J, Lebwohl D, Jehl V, Wolin EM, et al. 2011 Everolimus plus octreotide long-acting repeatable for the treatment of advanced neuroendocrine tumours associated with carcinoid syndrome (RADIANT-2): a randomised, placebo-controlled, phase 3 study. Lancet 378 2005-2012. (https://doi.org/10.1016/S01406736(11)61742-X)

Pavel ME, Baudin E, Oberg KE, Hainsworth JD, Voi M, Rouyrre N, Peeters M, Gross DJ \& Yao JC 2017 Efficacy of everolimus plus octreotide LAR in patients with advanced neuroendocrine tumor and carcinoid syndrome: final overall survival from the randomized, (c) 2021 Society for Endocrinology Published by Bioscientifica Ltd. Printed in Great Britain 
placebo-controlled phase 3 RADIANT-2 study. Annals of Oncology 28 1569-1575. (https://doi.org/10.1093/annonc/mdx193)

Pea A, Yu J, Marchionni L, Noe M, Luchini C, Pulvirenti A, de Wilde RF, Brosens LA, Rezaee N, Javed A, et al. 2020 Genetic analysis of small well-differentiated pancreatic neuroendocrine tumors identifies subgroups with differing risks of liver metastases. Annals of Surgery 271 566-573. (https://doi.org/10.1097/SLA.0000000000003022)

Pellat A \& Coriat R 2020 Well differentiated grade 3 neuroendocrine tumors of the digestive tract: a narrative review. Journal of Clinical Medicine 9 1677. (https://doi.org/10.3390/jcm9061677)

Pelosi G, Sonzogni A, Harari S, Albini A, Bresaola E, Marchio C, Massa F, Righi L, Gatti G, Papanikolaou N, et al. 2017 Classification of pulmonary neuroendocrine tumors: new insights. Translational Lung Cancer Research 6 513-529. (https://doi.org/10.21037/tlcr.2017.09.04)

Peppicelli S, Andreucci E, Ruzzolini J, Bianchini F \& Calorini L 2020 FDG uptake in cancer: a continuing debate. Theranostics 10 2944-2948. (https://doi.org/10.7150/thno.40599)

Pereira SS, Pereira R, Santos AP, Costa MM, Morais T, Sampaio P, Machado B, Afonso LP, Henrique R \& Monteiro MP 2019 Higher IL-6 peri-tumoural expression is associated with gastro-intestinal neuroendocrine tumour progression. Pathology 51 593-599. (https:// doi.org/10.1016/j.pathol.2019.07.001)

Poiana C, Neamtu MC, Avramescu ET, Carsote M, Trifanescu R, Terzea D, Neamtu OM \& Danciulescu Miulescu R 2013 The dedifferentiation of neuroendocrine tumor metastases: myth or reality? Romanian Journal of Morphology and Embryology 54 201-203.

Quinn AM, Chaturvedi A \& Nonaka D 2017 High-grade neuroendocrine carcinoma of the lung with carcinoid morphology: a study of 12 cases. American Journal of Surgical Pathology 41 263-270. (https://doi. org/10.1097/PAS.0000000000000767)

Rahman MM, Qian ZR, Wang EL, Yoshimoto K, Nakasono M, Sultana R, Yoshida T, Hayashi T, Haba R, Ishida M, et al. 2010 DNA methyltransferases $1,3 \mathrm{a}$, and $3 \mathrm{~b}$ overexpression and clinical significance in gastroenteropancreatic neuroendocrine tumors. Human Pathology 41 1069-1078. (https://doi.org/10.1016/j. humpath.2010.01.011)

Rekhtman N, Pietanza MC, Hellmann MD, Naidoo J, Arora A, Won H, Halpenny DF, Wang H, Tian SK, Litvak AM, et al. 2016 Nextgeneration sequencing of pulmonary large cell neuroendocrine carcinoma reveals small cell carcinoma-like and non-small cell carcinoma-like subsets. Clinical Cancer Research 22 3618-3629. (https://doi.org/10.1158/1078-0432.CCR-15-2946)

Richards-Taylor S, Tilley C, Jaynes E, Hu H, Armstrong T, Pearce NW, Plant R \& Cave J 2017 Clinically significant differences in Ki-67 proliferation index Between primary and metastases in resected pancreatic neuroendocrine tumors. Pancreas 46 1354-1358. (https:// doi.org/10.1097/MPA.0000000000000933)

Roldo C, Missiaglia E, Hagan JP, Falconi M, Capelli P, Bersani S, Calin GA, Volinia S, Liu CG, Scarpa A, et al. 2006 MicroRNA expression abnormalities in pancreatic endocrine and acinar tumors are associated with distinctive pathologic features and clinical behavior. Journal of Clinical Oncology 24 4677-4684. (https://doi. org/10.1200/JCO.2005.05.5194)

Rosenau J, Bahr MJ, von Wasielewski R, Mengel M, Schmidt HH, Nashan B, Lang H, Klempnauer J, Manns MP \& Boeker KH 2002 $\mathrm{Ki} 67, \mathrm{E}$-cadherin, and p53 as prognostic indicators of long-term outcome after liver transplantation for metastatic neuroendocrine tumors. Transplantation 73 386-394. (https://doi. org/10.1097/00007890-200202150-00012)

Rossi RE, Garcia-Hernandez J, Meyer T, Thirlwell C, Watkins J, Martin NG, Caplin ME \& Toumpanakis C 2015 Chromogranin A as a predictor of radiological disease progression in neuroendocrine tumours. Annals of Translational Medicine 3 118. (https://doi. org/10.3978/j.issn.2305-5839.2015.04.23)

Samani AA, Yakar S, LeRoith D \& Brodt P 2007 The role of the IGF system in cancer growth and metastasis: overview and recent insights. Endocrine Reviews 28 20-47. (https://doi.org/10.1210/ er.2006-0001)

Samsom KG, van Veenendaal LM, Valk GD, Vriens MR, Tesselaar MET \& van den Berg JG 2019 Molecular prognostic factors in smallintestinal neuroendocrine tumours. Endocrine Connections 8 906-922. (https://doi.org/10.1530/EC-19-0206)

Scarpa A 2019 The landscape of molecular alterations in pancreatic and small intestinal neuroendocrine tumours. Annales d'Endocrinologie $\mathbf{8 0}$ 153-158. (https://doi.org/10.1016/j.ando.2019.04.010)

Scarpa A, Chang DK, Nones K, Corbo V, Patch AM, Bailey P, Lawlor RT, Johns AL, Miller DK, Mafficini A, et al. 2017 Whole-genome landscape of pancreatic neuroendocrine tumours. Nature 543 65-71. (https://doi.org/10.1038/nature21063)

Semba S, Kusumi R, Moriya T \& Sasano H 2000 Nuclear accumulation of B-catenin in human endocrine tumors: association with Ki-67 (MIB1) proliferative activity. Endocrine Pathology 11 243-250. (https://doi. org/10.1385/ep:11:3:243)

Shi H, Zhang Q, Han C, Zhen D \& Lin R 2018 Variability of the Ki-67 proliferation index in gastroenteropancreatic neuroendocrine neoplasms - a single-center retrospective study. BMC Endocrine Disorders 18 51. (https://doi.org/10.1186/s12902-018-0274-y)

Simbolo M, Mafficini A, Sikora KO, Fassan M, Barbi S, Corbo V, Mastracci L, Rusev B, Grillo F, Vicentini C, et al. 2017 Lung neuroendocrine tumours: deep sequencing of the four World Health Organization histotypes reveals chromatin-remodelling genes as major players and a prognostic role for tert, RB1, MEN1 and KMT2D. Journal of Pathology 241 488-500. (https://doi.org/10.1002/ path.4853)

Simbolo M, Vicentini C, Mafficini A, Fassan M, Pedron S, Corbo V, Mastracci L, Rusev B, Pedrazzani C, Landoni L, et al. 2018 Mutational and copy number asset of primary sporadic neuroendocrine tumors of the small intestine. Virchows Archiv 473 709-717. (https://doi.org/10.1007/s00428-018-2450-x)

Simbolo M, Barbi S, Fassan M, Mafficini A, Ali G, Vicentini C, Sperandio N, Corbo V, Rusev B, Mastracci L, et al. 2019 Gene expression profiling of lung atypical carcinoids and large cell neuroendocrine carcinomas identifies three transcriptomic subtypes with specific genomic alterations. Journal of Thoracic Oncology 14 1651-1661. (https://doi.org/10.1016/j.jtho.2019.05.003)

Singhi AD \& Klimstra DS 2018 Well-differentiated pancreatic neuroendocrine tumours (PanNETs) and poorly differentiated pancreatic neuroendocrine carcinomas (PanNECs): concepts, issues and a practical diagnostic approach to high-grade (G3) cases. Histopathology 72 168-177. (https://doi.org/10.1111/his.13408)

Singh S, Hallet J, Rowsell C \& Law CH 2014 Variability of Ki67 labeling index in multiple neuroendocrine tumors specimens over the course of the disease. European Journal of Surgical Oncology 40 1517-1522. (https://doi.org/10.1016/j.ejso.2014.06.016)

Singhi AD, Liu TC, Roncaioli JL, Cao D, Zeh HJ, Zureikat AH, Tsung A, Marsh JW, Lee KK, Hogg ME, et al. 2017 Alternative lengthening of telomeres and loss of DAXX/ATRX expression predicts metastatic disease and poor survival in patients with pancreatic neuroendocrine tumors. Clinical Cancer Research 23 600-609. (https://doi. org/10.1158/1078-0432.CCR-16-1113)

Stalberg P, Westin G \& Thirlwell C 2016 Genetics and epigenetics in small intestinal neuroendocrine tumours. Journal of Internal Medicine 280 584-594. (https://doi.org/10.1111/joim.12526)

Starzynska T, Karczmarski J, Paziewska A, Kulecka M, Kusnierz K, ZeberLubecka N, Ambrozkiewicz F, Mikula M, Kos-Kudla B \& Ostrowski J 2020 Differences between well-differentiated neuroendocrine tumors and ductal adenocarcinomas of the pancreas assessed by multi-omics profiling. International Journal of Molecular Sciences 21 4470. (https:// doi.org/10.3390/ijms21124470)

Stefanoli M, La Rosa S, Sahnane N, Romualdi C, Pastorino R, Marando A, Capella C, Sessa F \& Furlan D 2014 Prognostic relevance of aberrant DNA methylation in g1 and g2 pancreatic https://erc.bioscientifica.com

https://doi.org/10.1530/ERC-20-0473
C) 2021 Society for Endocrinology Published by Bioscientifica Ltd. Printed in Great Britain 
neuroendocrine tumors. Neuroendocrinology 100 26-34. (https://doi. org/10.1159/000365449)

Tang LH, Untch BR, Reidy DL, O'Reilly E, Dhall D, Jih L, Basturk O, Allen PJ \& Klimstra DS 2016 Well-differentiated neuroendocrine tumors with a morphologically apparent high-grade component: a pathway distinct from poorly differentiated neuroendocrine carcinomas. Clinical Cancer Research 22 1011-1017. (https://doi. org/10.1158/1078-0432.CCR-15-0548)

Thomas GV, Tran C, Mellinghoff IK, Welsbie DS, Chan E, Fueger B, Czernin J \& Sawyers CL 2006 Hypoxia-inducible factor determines sensitivity to inhibitors of mTOR in kidney cancer. Nature Medicine 12 122-127. (https://doi.org/10.1038/nm1337)

Tirosh A \& Kebebew E 2018 The utility of (68)Ga-DOTATATE positron-emission tomography/computed tomography in the diagnosis, management, follow-up and prognosis of neuroendocrine tumors. Future Oncology 14 111-122. (https://doi.org/10.2217/ fon-2017-0393)

Travis WD, Brambilla E, Burke A, Marx A \& Nicholson AG 2015 WHO Classification of Tumours of the Lung, Pleura, Thymus and Heart. International Agency for Research on Cancer (IARC)

Tsoli M, Alexandraki K, Xanthopoulos C, Kassi E \& Kaltsas G 2020 Medical treatment of gastrointestinal neuroendocrine neoplasms. Hormone and Metabolic Research 52 614-620. (https://doi. org/10.1055/a-1110-7251)

Uemura J, Okano K, Oshima M, Suto H, Ando Y, Kumamoto K, Kadota K, Ichihara S, Kokudo Y, Maeba T, et al. 2019 Immunohistochemically detected expression of ATRX, TSC2, and PTEN predicts clinical outcomes in patients with grade 1 and 2 pancreatic neuroendocrine tumors. Annals of Surgery [epub]. (https:// doi.org/10.1097/SLA.0000000000003624)

Vandamme T, Beyens M, de Beeck KO, Dogan F, van Koetsveld PM, Pauwels P, Mortier G, Vangestel C, de Herder W, Van Camp G, et al. 2016 Long-term acquired everolimus resistance in pancreatic neuroendocrine tumours can be overcome with novel PI3K-AKTmTOR inhibitors. British Journal of Cancer 114 650-658. (https://doi. org/10.1038/bjc.2016.25)

Vandamme T, Beyens M, Boons G, Schepers A, Kamp K, Biermann K, Pauwels P, De Herder WW, Hofland LJ, Peeters M, et al. 2019 Hotspot DAXX, PTCH2 and CYFIP2 mutations in pancreatic neuroendocrine neoplasms. Endocrine-Related Cancer 26 1-12. (https://doi. org/10.1530/ERC-18-0120)

Visvader JE \& Lindeman GJ 2008 Cancer stem cells in solid tumours: accumulating evidence and unresolved questions. Nature Reviews: Cancer 8 755-768. (https://doi.org/10.1038/nrc2499)

von Arx C, Capozzi M, Lopez-Jimenez E, Ottaiano A, Tatangelo F, Di Mauro A, Nasti G, Tornesello ML \& Tafuto S 2019 Updates on the role of molecular alterations and NOTCH signalling in the development of neuroendocrine neoplasms. Journal of Clinical Medicine 8 1277. (https://doi.org/10.3390/jcm8091277)
Waldum HL, Oberg K, Sordal ØF, Sandvik AK, Gustafsson BI, Mjones P \& Fossmark R 2018 Not only stem cells, but also mature cells, particularly neuroendocrine cells, may develop into tumours: time for a paradigm shift. Therapeutic Advances in Gastroenterology 11 1756284818775054. (https://doi.org/10.1177/1756284818775054)

Weiss V, Dueber J, Wright JP, Cates J, Revetta F, Parikh AA, Merchant NB \& Shi C 2016 Immunohistochemical analysis of the Wnt/betacatenin signaling pathway in pancreatic neuroendocrine neoplasms. World Journal of Gastrointestinal Oncology 8 615-622. (https://doi. org/10.4251/wjgo.v8.i8.615)

WHO 2019 Classification of Tumors, Digestive System Tumors WHO Classification of Tumors, Vol. 1, 5th ed., pp. 17-19. Lyon: International Agency for Research on Cancer.

Wong SHM, Fang CM, Chuah LH, Leong CO \& Ngai SC 2018 E-cadherin: its dysregulation in carcinogenesis and clinical implications. Critical Reviews in Oncology/Hematology 121 11-22. (https://doi.org/10.1016/j.critrevonc.2017.11.010)

Yachida S, Vakiani E, White CM, Zhong Y, Saunders T, Morgan R, de Wilde RF, Maitra A, Hicks J, Demarzo AM, et al. 2012 Small cell and large cell neuroendocrine carcinomas of the pancreas are genetically similar and distinct from well-differentiated pancreatic neuroendocrine tumors. American Journal of Surgical Pathology $\mathbf{3 6}$ 173-184. (https://doi.org/10.1097/PAS.0b013e3182417d36)

Yao JC, Phan AT, Chang DZ, Wolff RA, Hess K, Gupta S, Jacobs C, Mares JE, Landgraf AN, Rashid A, et al. 2008 Efficacy of RAD001 (everolimus) and octreotide LAR in advanced low- to intermediategrade neuroendocrine tumors: results of a phase II study. Journal of Clinical Oncology 26 4311-4318. (https://doi.org/10.1200/ JCO.2008.16.7858)

Yao JC, Shah MH, Ito T, Bohas CL, Wolin EM, Van Cutsem E, Hobday TJ, Okusaka T, Capdevila J, de Vries EG, et al. 2011 Everolimus for advanced pancreatic neuroendocrine tumors. New England Journal of Medicine 364 514-523. (https://doi.org/10.1056/ NEJMoa1009290)

Yonemori K, Kurahara H, Maemura K, Mataki Y, Sakoda M, Iino S, Ueno S, Shinchi H \& Natsugoe S 2017 Impact of Snail and E-cadherin expression in pancreatic neuroendocrine tumors. Oncology Letters 14 1697-1702. (https://doi.org/10.3892/ol.2017.6306)

Yu P, Sa C, Xiaobing F \& Andong Z 2014 p53: the barrier or guardian for cell dedifferentiation? BioScience 64 883-892. (https://doi. org/10.1093/biosci/biu133)

Zandee WT, Kamp K, van Adrichem RC, Feelders RA \& de Herder WW 2017 Effect of hormone secretory syndromes on neuroendocrine tumor prognosis. Endocrine-Related Cancer 24 R261-R274. (https:// doi.org/10.1530/ERC-16-0538)

Zatelli MC, Guadagno E, Messina E, Lo Calzo F, Faggiano A, Colao A \& NIKE Group 2018 Open issues on G3 neuroendocrine neoplasms: back to the future. Endocrine-Related Cancer 25 R375-R384. (https:// doi.org/10.1530/ERC-17-0507)

Received in final form 12 February 2021

Accepted 6 April 2021

Accepted Manuscript published online 6 April 2021
C) 2021 Society for Endocrinology Published by Bioscientifica Ltd. Printed in Great Britain 